University of Louisville

ThinkIR: The University of Louisville's Institutional Repository

Electronic Theses and Dissertations

$5-2013$

\title{
The effects of online courses with multimedia in learners' perceived satisfaction and effectiveness of e-learning.
}

Hardy MacKenzie 1971-

University of Louisville

Follow this and additional works at: https://ir.library.louisville.edu/etd

\section{Recommended Citation}

MacKenzie, Hardy 1971-, "The effects of online courses with multimedia in learners' perceived satisfaction and effectiveness of e-learning." (2013). Electronic Theses and Dissertations. Paper 876.

https://doi.org/10.18297/etd/876

This Doctoral Dissertation is brought to you for free and open access by ThinkIR: The University of Louisville's Institutional Repository. It has been accepted for inclusion in Electronic Theses and Dissertations by an authorized administrator of ThinkIR: The University of Louisville's Institutional Repository. This title appears here courtesy of the author, who has retained all other copyrights. For more information, please contact thinkir@louisville.edu. 


\title{
THE EFFECTS OF ONLINE COURSES WITH MULTIMEDIA IN LEARNERS' PERCEIVED SATISFACTION AND EFFECTIVENESS OF E-LEARNING
}

\author{
By \\ Hardy MacKenzie \\ B.S.B.A., University of Louisville, 1998 \\ MEd, University of Louisville, 2002

\begin{abstract}
A Dissertation
Submitted to the Faculty of the

College of Education of the University of Louisville

in Partial Fulfillment of the Requirements

for the Degree of
\end{abstract} \\ Doctor of Philosophy \\ College of Education and Human Development \\ University of Louisville \\ Louisville, Kentucky
}

May 2013 
Copyright 2013 by Hardy MacKenzie

All rights reserved 


\title{
THE EFFECTS OF ONLINE COURSES WITH MULTIMEDIA IN LEARNERS' PERCEIVED SATISFACTION AND EFFECTIVENESS OF E-LEARNING
}

\author{
By
}

Hardy MacKenzie

B.S.B.A., University of Louisville, 1998

MEd, University of Louisville, 2002

A Dissertation Approved on

April 8, 2013

by the following Dissertation Committee:

Dr. Brad Shuck

Dissertation Director

Dr. Rod Patrick Githens

Dr. Meera Alagaraja

Dr. Carolyn Rude-Parkins

Dr. Marion Hambrick 


\section{DEDICATION}

I dedicate this work to my parents, Adrian and Dorita MacKenzie, for having devoted countless hours in my formation and guidance. To my sister Diane, for always providing me with the support and motivation to keep on achieving bigger and better goals in life (The Sky is the Limit - Diane MacKenzie); to my sister Kathleen, for being a role model in the road of academic achievements. To my aunt Yoly Corzantes, and my grandparents Ruben and Martita Corzantes, for their contribution to my development and

formation; to Dr. Brad Shuck, for being such a beacon of knowledge and an inspiration to conduct research and achieve results and to Dean Brooks for being my motivator and mentor in a balanced and healthy life-style - Always Forward! 


\section{ACKNOWLEDGMENTS}

I would like to acknowledge a profound sense of gratitude and admiration to the outstanding members of my dissertation committee: Dr. Brad Shuck for serving as my academic mentor and dissertation chair; Dr. Rod Githens and Dr. Meera Alagaraja for their continued support and dedication during the process of my dissertation; Dr. Marion Hambrick, for his commitment to education and quality of student outcomes and Dr. Carolyn Rude-Parkins for her mentorship through my entire graduate career and her guidance to a successful professional career.

I also would like to acknowledge Dr. Mike Boyle, Rachel Maloney, Daniel Hamm, Dr. Paul Winter, Greg Rosa, Kaleena Woodrum, Amelia Williams, Dr. Rachel DeMuth, Kelly Young, Steve Hudson, David Bannister Jr., and Pilar Abreu, who dedicated their time to provide me with feedback, guidance, opinions, perspectives, data and resources to complete this work. I like to especially acknowledge Susan Ehringer, for her efficient and high quality work on the course that provided the retrospective data for this study; to Jerry and Rosie Wiebusch, for their many years of unconditional support and family love.

Last, I like to acknowledge Humana Inc., for promoting an engaging workplace and providing me with the latitude for real life applications of knowledge acquired during my academic years. 


\section{ABSTRACT \\ THE EFFECTS OF ONLINE COURSES WITH MULTIMEDIA IN LEARNERS' PERCEIVED SATISFACTION AND EFFECTIVENESS OF E-LEARNING}

\section{Hardy MacKenzie}

April 8, 2013

The purpose of this exploratory study was to determine how the use of multimedia components, such as graphics, audio and video, in online courses was related to perceived learner satisfaction and learning effectiveness. The use of retrospective data provided self reported perceived satisfaction measures and total score representing objective performance in an online course. Data represented employees of a large multinational, publicly traded healthcare company $(N=2401)$ during the 2012 calendar year. The independent variables were: (a) learner perceived satisfaction with the use of graphics, (b) learner perceived satisfaction with the use of audio, (c) learner perceived satisfaction with the use of narration properly synchronized with text animation, (d) learner perceived satisfaction with the use of video, and (e) reason for enrolling in the online course. The dependent variable was learner's objective performance score.

Correlations and hierarchical logistic regression were performed on the data. Major findings include (a) a low relation between learners' perceived satisfaction with the use of graphics and objective performance, (b) a relation between combined learners' perceived satisfaction with the use of audio, learners' perceived satisfaction with the use of narration properly synchronized with text animation, and learners' perceived satisfaction with the use of video and learners' objective performance $\left(r^{2}=.001, p<.05\right)$, 
and (c) reason for enrolling in the online course did not predict learners' objective performance. The study presented additional conclusions and implications for theory, research, and practice. 


\section{TABLE OF CONTENTS}

PAGE

\section{CHAPTER}

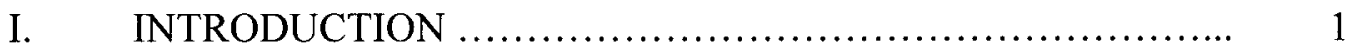

Purpose of the Study ................................. 5

Research Questions and Hypotheses...................... 5

Theoretical Framework ............................... 7

Generative Theory of Multimedia Learning......... 7

Cognitive Theory of Multimedia.................. 9

Significance $\ldots . \ldots \ldots \ldots \ldots \ldots \ldots \ldots \ldots \ldots \ldots \ldots \ldots \ldots, \quad 12$

Assumptions and Delimitations ........................ 13

Definitions and Terms ................................ 14

Organization of the Study............................... 15

II. LITERATURE REVIEW ..................................... 17

Multimedia in e-Learning........................... 17

Video.......................................... 20

Audio.......................................... 21

Multimedia Learning Theory............................ 24

Generative Theory of Multimedia Learning ............... 25

Generative process of Comprehension ............. 26

Dual Code Theory ............................... 27

Cognitive Theory of Multimedia Learning ................ 29

Learner Effectiveness..................................... 31

Learner Satisfaction.................................... 34

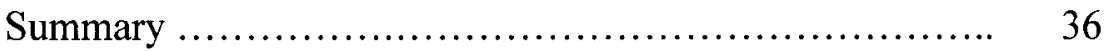

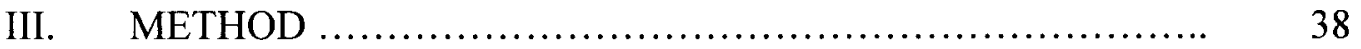

Purpose of the Study.................................. 38

Research Questions and Hypotheses ...................... 38

Research Design ......................................... 39

Population and Sample Size ........................... 39

Variables and Instrumentation......................... 41

Multimedia ........................................ 41 
Instrument.................................. 43

Final Score.................................... 47

Procedures ............................................ 48

Data Analysis................................. 50

Summary of Method................................. 52

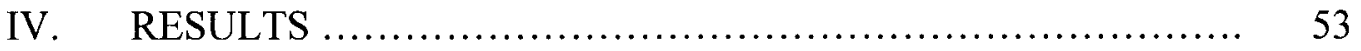

Background of the Sample.............................. 54

Current Role...................................... 54

Tenure in Current Role........................... 54

Reason for Enrolling........................... 55

Examination of Hypotheses........................... 55

Multicollinearity................................ 56

Correlation Analysis for Testing $\mathrm{H}_{1} \ldots \ldots \ldots \ldots \ldots \ldots . \quad 57$

Correlation Analysis for Testing $\mathrm{H}_{2} \ldots \ldots \ldots \ldots \ldots \ldots . \quad 58$

Correlation Analysis for Testing $\mathrm{H}_{3} \ldots \ldots \ldots \ldots \ldots \ldots . \quad 59$

Correlation Analysis for Testing $\mathrm{H}_{4} \ldots \ldots \ldots \ldots \ldots \ldots . \quad 59$

Hierarchical Regression Analysis for Testing $\mathrm{H}_{5} \ldots . .60$

Summary...................................... 63

V. DISCUSSION .............................................. 64

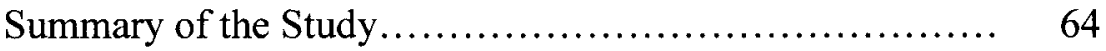

Discussion of Results..................................... 66

Hypothesis $1 \ldots \ldots \ldots \ldots \ldots \ldots \ldots \ldots \ldots \ldots \ldots \ldots . \ldots \ldots$

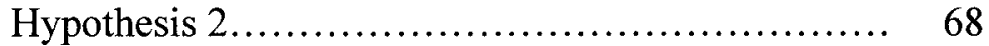

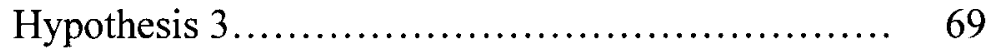

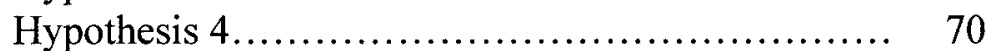

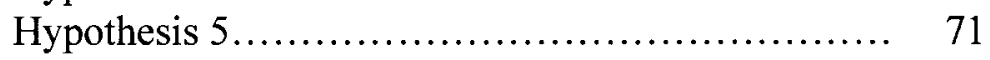

Implications for Theory, Research and Practice .......... 72

Implications for Theory......................... 73

Implications for Research...................... 75

Implications for Practice ........................ 78

Limitations of the Study............................. 80

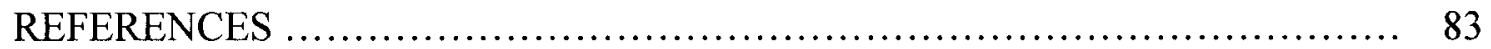

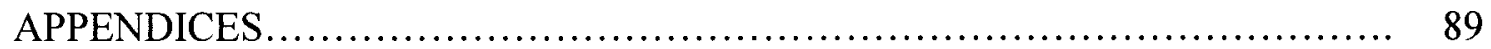

CURRICULUM VITA.................................................. 94 


\section{LIST OF TABLES}

TABLE

PAGE

1 Estimate of hours needed to develop one hour of web-based

training (Driscoll, 2002) ................................

2 The going rate (Driscoll, 2002) ............................ 23

3 A KPI framework at the position/role level (Wang et al. 2010)...... 33

$4 \quad$ Steps completed in Dillman et al (2009) Tailored Design Method... 44

$5 \quad$ Agreement five point Likert-scale used in the SPLD survey........ 45

6 Questions used to conduct hypotheses tests.................... 47

$7 \quad$ Frequency table of background variables ...................... 55

8 Zero-order correlation coefficients for learner objective performance and perceived satisfaction with use of graphics, perceived satisfaction with use of audio, perceived satisfaction with use of narration properly synchronized with text animation, and perceived satisfaction with use of video......................

9 Summary hierarchical regression analysis with learner perceived satisfaction with graphics, learner perceived satisfaction with audio, learner perceived satisfaction with narration properly synchronized with text animation, and learner perceived satisfaction with video, and reason for enrollment predicting performance. 


\section{LIST OF FIGURES}

FIGURE PAGE

1 The effect of multimedia in online course grades..................... 7

$2 \quad$ A generative model of multimedia learning (Mayer, 1997)............. 8

3 Cognitive theory of multimedia learning (Moreno \& Mayer, 2000)....... 10

4 Sample multimedia layout, Medicare online course (Medicare 101, 2012). 49

$5 \quad$ Predictors of objective performance............................. 72 


\section{CHAPTER I \\ INTRODUCTION}

E-learning is the umbrella term referring to all technologies used in the process of designing, delivering, and managing instruction using computers (Driscoll 2002). According to Clark and Mayer (2008), e-Learning is defined as training delivered on a computer that is designed to support individual learning or organizational performance goals. The widespread availability of the Internet and the ever-increasing bandwidth for telephone lines allow the use of rich media over long distances (Herder, Subrahmanian, Talukdar, Turk, \& Westerberg, 2002). As of November 2000 there were 407.1 million people logging online worldwide (Driscoll, 2002). The amount of people online represents the high amounts of potential learners that could benefit from the use of multimedia. The previous term of distance education has been replaced with the implementation and demand of e-Learning, referring to methods for people to learn subject matter remotely via the Internet. As expanding capabilities of the Internet allow increased speed and more complex technologies, and course developers can include multimedia components aimed at promoting active and meaningful learning (Bolliger, Supanakorn, \& Boggs, 2010).

Multimedia refers to a presentation that contains words, such as narration or onscreen text, and graphics, such as illustrations, photos, animations or video (Clark \& Mayer, 2008). E-Learning, also termed online course includes words in the form of text, 
and graphics in the form of illustrations and photos. Online courses that include words as onscreen text and narration and graphics in the form of photos, animations, or video improve students' applied-conceptual learning (Kekkonen-Moneta \& Moneta, 2002).

Notwithstanding, companies are leveraging e-Learning as an option to reduce cost of training and to reach audiences dispersed across a large geographical area (Driscoll, 2002). Vyas et al. (2010) described a need to consider a platform that allows for video, audio, and images to facilitate learning. In support, Hussein and Cronje (2010) mentioned the use of digital music players as effective means and styles of training capsules for the ever-changing learners in the workplace.

Course developers in the past have used words mainly in the form of onscreen text, and graphics in the form of illustration, photos, and animation to illustrate their content. Moreover, rapid advances in broadband access network technologies have allowed course developers to use text in the form of narration and graphics in the form of animation and video (Wingaarden et al., 2010). Graphics, animations, audio and video allow course developers to enrich and individualize content for learners (KekkonneMoneta \& Moneta, 2002).

In support, Driscoll (2002) mentioned tactical reasons for using e-Learning. Among these tactical reasons were the reduction of travel and related cost, ability to enable learning to occur at any time and any place, as well as to provide just-in-time learning. While the cost reduction reason seems merely for cost savings, the ability to allow for learning occurring at anytime and anyplace is a great tactic (Driscoll, 2002). Employees can learn needed knowledge for their daily job at their desk, at home, or during slow periods. The tactic that is becoming more prevalent is the use of just-in-time 
learning (JITL; Driscoll, 2002); this kind of learning allows employees to be more effective (Driscoll, 2002).

JITL offers the benefit to provide employees with content necessary to perform their immediate tasks by offering training to learners when they are most interested in learning (Leach \& Haun, 2003). In order for JTL to become accessible and be used as leverage, it is advantageous to take the form of asynchronous or online training, so that learners can complete programs at their desks, at home, or during slow periods (Driscoll, 2002). Learners can listen to podcasts to review the use of a process or view a short "how-to" video for just-in-time application of skills. In turn, this will keep organizations moving forward and minimize performance related downtime (Kutzik, 2005).

The approach of JITL uniquely opens the door for other multimedia resources available outside of the company's Intranet. The use of videos loaded to YouTube or the access to podcasts saved to iTunes provide employees with a plethora of informal learning resources (Meister, 2009). Ketter (2009) pointed out that informal learning is a "modernization of the learning function." Learners are receiving credit for watching video footage of lectures in YouTube (Meister, 2009). An important part of learning accounts for the ability to listen to lectures and to play them back multiple times in the form of a podcast (Meister, 2009).

As a result of this rapid development, educational institutions, course developers, and scholars are considering issues of satisfaction and effectiveness, among other factors, when suggesting development and delivery techniques for online learning content. For example, multimedia in learning has been studied by Guan (2009), Liaw (2008), Schilling (2009), Zheng, Yang, Garcia and McCadden (2008) as a variable to measure its 
effectiveness as a form of instruction. Rodriguez et al., (2008), Morgan (2007), and Lei and Gupta (2010) have examined satisfaction and behavioral intention as learner variables, and in most cases they have found that online learning effectiveness has a correlation with the learner behavioral intent of using e-Learning. Furthermore, research has suggested that learners have the potential to strengthen effectiveness and heighten their interest in a given subject matter when they can access multimedia resources (Diezmann \& Watters, 2002). Learners using e-Learning courses that included modules with multimedia elements such as audio narration, video and carefully designed animation, demonstrated higher-order learning outcomes (Kekkonen-Moneta \& Moneta, 2002).

Moller et al. (2008) indicated the cost of training may be lowered when eLearning is used more. The use of e-Learning makes it scalable because companies do not have to invest in travel arrangements to train their workforces; by having more content delivered via e-Learning more employees will have the ability to access the learning content even if they are physically located in different geographical points (Driscoll, 2002).

Liaw (2008) suggested that multimedia formats are becoming a vital component in the development of effective e-Learning. While one of the main purposes of a learning department within an organization is to develop e-Learning quickly to satisfy the fast changing needs of employees (Driscoll, 2000), it is important to produce e-Learning that is engaging (Liaw, 2008), provides employees with satisfaction, and gives them a sense of effectiveness (Zhang, 2005). Use of well-developed e-Learning programs that incorporate multimedia components can result in high levels of employee learning 
effectiveness and satisfaction. The increase of skills and knowledge provide such outcomes as selling and servicing more products and completing work faster and with fewer errors, which in turn increase profitability and improve productivity (Driscoll, 2002). Little research has analyzed the relationship of the multimedia components of animation, audio and video as part of e-Learning courses and the variables of learner satisfaction and learning effectiveness.

\section{Purpose of the Study}

The purpose of this study was to determine how the use of multimedia components, such as animation, audio and video, in online courses was related to perceived learner satisfaction and learning effectiveness.

\section{Research Questions and Hypotheses}

Two overarching research questions guided this study: (a) is there a relationship between learners' perceived satisfaction of a course and the use of graphics, audio, narration properly synchronized with the text animation and video in the course? and (b) does the reason for enrolling in a course predict the learner score of an online course that contains multimedia? To explore these research questions, five hypotheses were proposed for examination:

$H_{I}$ : There is a positive relation between learners' objective performance and perceived satisfaction with the use of graphics in an online course.

$H_{2}$ : There is a positive relation between learners' objective performance and perceived satisfaction with the use of audio in the course. 
$H_{3}$ : There is a positive relation between learners' objective performance and perceived satisfaction with the narration properly synchronized with the text animation of the course.

$H_{4}$ : There is a positive relation between learners' objective performance and perceived satisfaction with video used in the course.

$H_{5}$ : After controlling for learners' perceived satisfaction with the use of graphics, learners' perceived satisfaction with the use of audio, learners' perceived satisfaction with the use of narration properly synchronized with text animation and learners' perceived satisfaction with the use of video, the reason for enrolling in the course will predict learners' performance.

The hypothesis model examined in this research study is illustrated in Figure 1. As suggested in the model, the use of multimedia elements such as audio, video and animation in conjunction with the traditional multimedia elements of text and graphics have an effect on learner satisfaction and effectiveness. The course grade is a quantitative measure influenced by (a) the learner satisfaction as a result of encountering multimedia elements, and (b) the learner effectiveness affected by multimedia elements. Last, the reason for the learner enrolling in the online course predicts the learner final grade. 
Learner

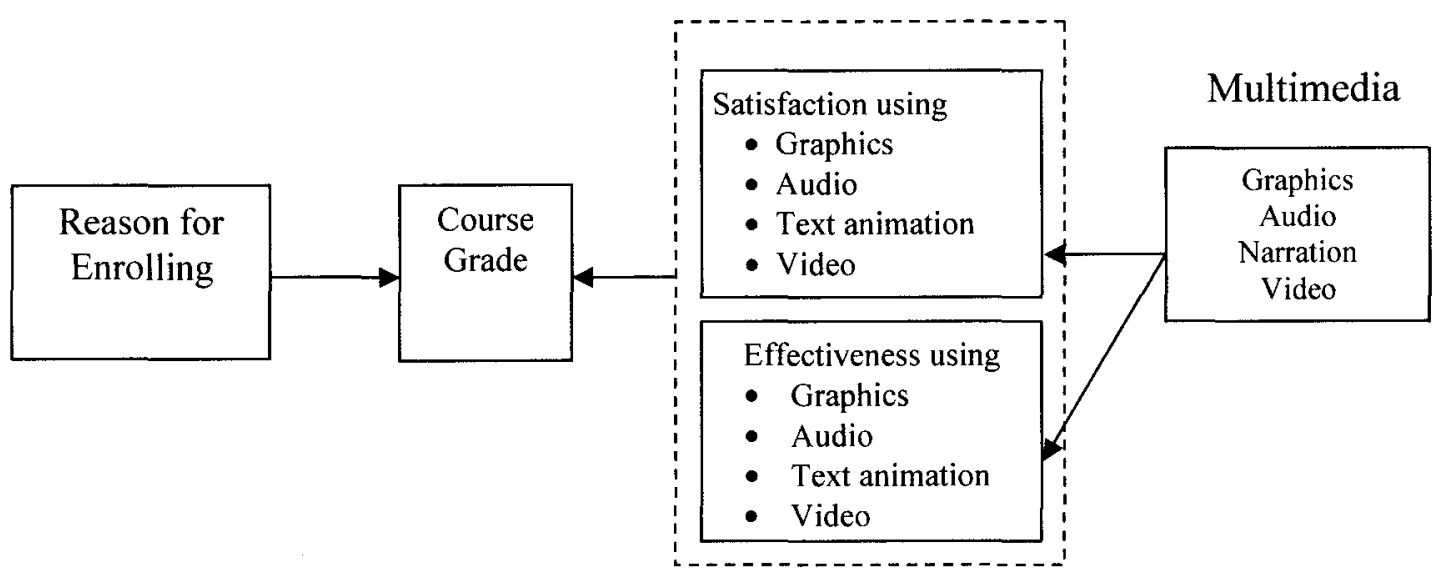

Figure 1. The effect of multimedia in online course grades.

\section{Theoretical Framework}

This study drew from two theories: (a) the generative theory of multimedia learning proposed by Mayer (1997), and (b) the cognitive theory of multimedia learning presented by Moreno and Mayer (2000). The following section explores each in brief.

\section{Generative Theory of Multimedia Learning}

The generative theory of multimedia presented by Mayer (1997), drawn from Wittrock's $(1974,1989)$ generative theory, and Paivio's (1986; Clark \& Paivio, 1991) dual coding theory is used by Diezmann and Watters (2002), to support a theoretical framework for multimedia resources. This theory supports the benefits of multimedia use in learning. Mayer's generative theory of multimedia learning accounts for meaningful learning, where learners integrate verbal and visual information presented with multimedia during the learning process.

Mayer (1997) describes the advancement of technology for multimedia education and yet, a less than equivalent advancement of understanding how people absorb 
knowledge in a multimedia based environment. Learners are presented with new technologies such as portable devices and smart phones (Choi \& Johnson, 2005). They are also presented with new multimedia platforms such as YouTube (Meister, 2009) and iTunes; these platforms provide learners with an array of content presented in multimedia formats such as audio and video or audio alone.

However, it is important to note that learners, consumers of the multimedia presented in e-Learning content, are affected at the satisfaction and effectiveness level. Course developers need to consider these elements of satisfaction and effectiveness when leveraging the use of multimedia for learning. They should be mindful that the learning process can be affected depending on the inclusion and use of multimedia in e-Learning (Driscoll, 2002). Mayer (1997) explained that learners go through the process of attending, organizing, and integrating data when absorbing information as shown on Figure 2. The process of attending is essentially the selection of words presented in text format and the selection of images presented in the illustration format. The learner takes the selected words and illustrations and organizes them in a relevant order to create the verbally-based and the visually based models. Mayer (1997) then proposed that the learner will integrate the verbal and visual based models to create knowledge.

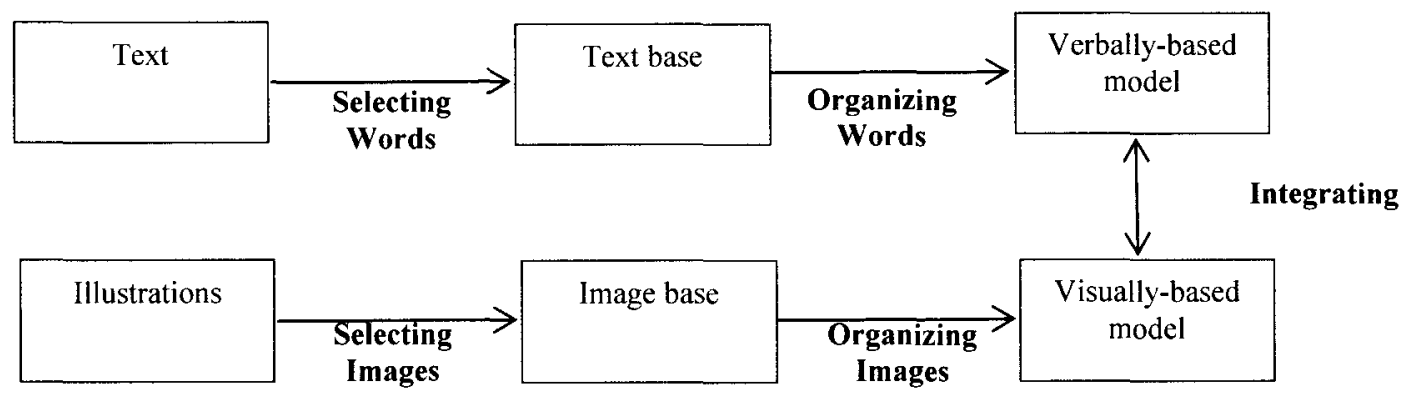

Figure 2. A generative model of multimedia learning (Mayer, 1997, p.5) 
Mayer's (1997) generative model of multimedia learning draws from the generative process comprehension presented by Wittrock (1990). The generative process is based on four actions: (a) generation, (b) motivation, (c) attention, and (d) memory. The generative process actions influenced the examination of the learning strategies. Wittrock (1990) recalled that imagery has played a central role in memory and associations among ideas have played a main role in retrieval. The process of generating interactive images between the old ideas and the new events serves as the foundation of the model. Learners have the ability to select words and images, based on their motivation to learn about something, to store them in working memory. The learner focuses attention, takes the text and images stored in working memory, and organizes them to create meaning. The meaning is the process of building relationships between the selected and organized text and images and what the learner knows, experiences and believes (Wittrock, 1990).

\section{Cognitive Theory of Multimedia}

In Moreno and Mayer's (2000) literature review, learners select the relevant information presented to them via the audio or visual channels. Learners organize such relevant information in meaningful mental representation in working memory and then integrate it with existing information stored in long-term memory as shown in Figure 3. 


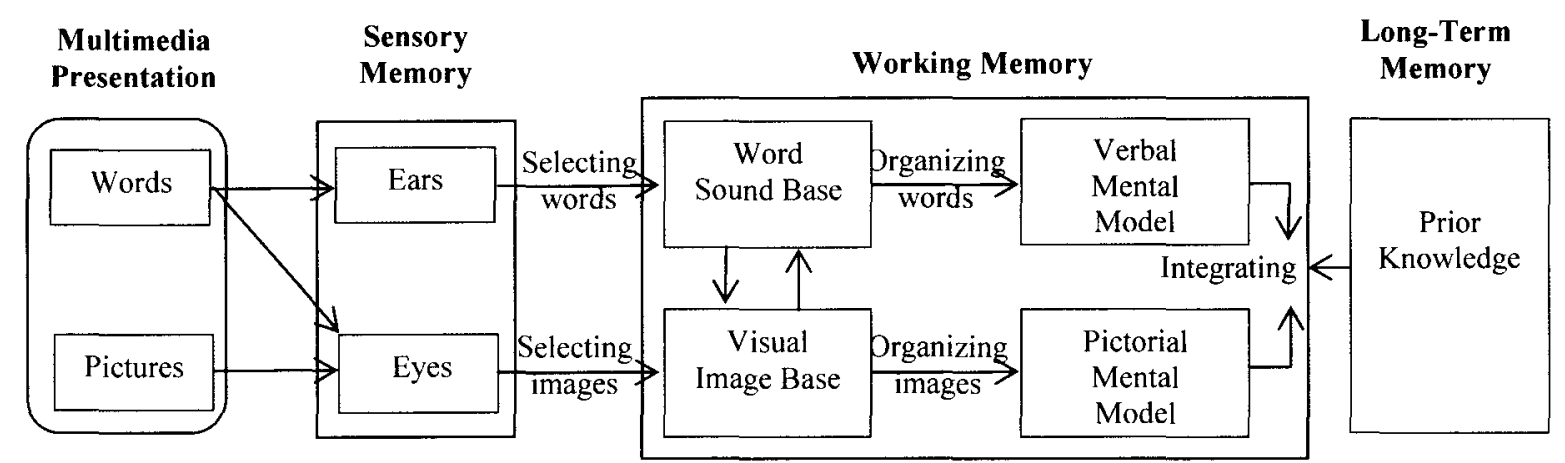

Figure 3. Cognitive theory of multimedia learning (Moreno \& Mayer, 2000)

Employees in organizations sometimes have to refresh skills or concepts to apply in tasks that lack frequent use in the work place. Course developers are tasked with providing job aids and regular training sessions, which can result in solutions that carry a cost or require logistical details to conduct sessions. Online training can provide a Just-inTime Learning approach (Driscoll, 2002). Multimedia presentations can influence the learner's working memory to organize the words and visual images to integrate with the knowledge stored in the long-term memory.

Mayer (1997) explains that learners use the technological platforms or readily available resources to find and select further information, sort it in conjunction with what they already know, and integrate it in such a way that they have a better understanding of the topic. This theory helps as a blueprint for course developers so they can leverage the use of multimedia in online courses. Multimedia presentations should include words and pictures that are absorbed by the learners' ears and eyes in the sensory memory. These words and pictures provide a base for the learners' working memory to perform the selection and organization of words and images by the verbal mental model and the pictorial mental model. In turn, the organization of words and images can finally be integrated with information stored in the learners' long-term memory. 
The model of cognitive theory of multimedia learning describes the equivalent of an employee needing to refresh the steps to complete a task. The employee may have learned the task some time ago. Due to the lack of performing the task, information is stored in long-term memory as prior knowledge, and must be integrated with information retrieved from a multimedia presentation. It is possible that learners are satisfied with the multimedia presentation because it is a fast and convenient way for the learner to acquire information. In addition the multimedia presentation provides variety of mediums that can enhance the knowledge in working memory, also labeled as knowledge transfer.

Training departments measure the employee performance with job performance (Gilbert, 1976). Depending on the job type, the measure recommended will vary (Gilbert, 1976). Generally, most employees perform a task, and the learning of tasks is measured by type, where some are measured by the speed and accuracy of a completed task, and others are measured by the quality or amount (Gilbert, 1976). Huff-Eibl et al. (2011) describe the importance of performance assessment based on the job description and the competencies necessary to perform the job. The competencies or behaviors necessary to complete a task can be weighed numerically by assigning a score (Huff-Eibl et al., 2011).

A score can be used as an indicator of the knowledge transfer effectiveness from an online course. Another relevant fact to note is how much training content or acquired knowledge employees retain one month, six months, or one year after the initial training (Cekada, 2011). Previously acquired knowledge becomes a part of the prior knowledge, and it is at that point where the use of multimedia presentations can provide the learner with a refresher of the knowledge in working memory to integrate it with long term memory. This is where the cognitive theory of multimedia learning is relevant. 


\section{Significance}

Organizations consider online learning as a strategic and tactical advantage (Driscoll, 2002). Multimedia components, such as audio, video, and animation are important components in effective online learning design (Liaw, 2004). Multimedia enables learners to develop complex cognitive skills (Liaw, 2004). This study explored the relationship of multimedia components and learner satisfaction and effectiveness in online learning. It tested a model that suggests that incorporating multimedia components in online learning can influence the learners' satisfaction and effectiveness.

This study aimed to support models of cognitive theory of multimedia (Moreno \& Mayer, 2000) and the generative theory of multimedia learning (Mayer, 1997). It also aimed at supporting the use of specific elements in multimedia presentations to generate knowledge with online resources, to influence the effect in student satisfaction and effectiveness.

Existing research by Diezmann and Watters (2002), and Liaw (2008) examine the use of multimedia as a secondary component when evaluating e-Learning methods. This study provided support to continue assessing the effect of multimedia elements use in eLearning. Further research results could be used in other fields of study (e.g., marketing, communications) to determine the satisfaction and effectiveness of inclusion of multimedia variables in field-specific materials such as informational advertising and behavior related communications.

Additionally, the knowledge generated by this study could help course developers in learning groups support the need to include multimedia elements in online courses, to obtain the most optimal results while using these elements purposefully. The inclusion of 
multimedia by course developers helps support the tactical reason of enabling learning any time and any place (Driscoll, 2002). Results of this study can strengthen the business case to use multimedia.

\section{Assumptions and Delimitations of the Study}

The following are assumptions and delimitations of this study.

\section{Assumptions}

Multimedia components included in online courses do not exceed the space capacity of the hosting platforms, constraining their availability to short duration. The

tools used to create multimedia components are of standard use by any course developer in a learning group.

\section{Delimitations}

This study contained four delimitations. The first delimitation was the use of non experimental research design. This type of design limited the ability to determine causality. The second delimitation was that the researcher used convenience sampling to procure a sample of learners who had taken or were in the process of taking an online course in the workplace. The lack of true random sample limits generalizability of the findings from this study.

In addition, this study explored the effects of multimedia elements in students' perceived satisfaction and effectiveness. However, the nature in which the retrospective data was collected permitted an item analysis instead of a scale analysis. The use of an item analysis does not provide strong results for the analysis. In addition, this study did not account for the varied learning styles of learners, which can have an influence in the results found. Therefore, the third delimitation of this study is the fact that it did not 
account for the learners' learning styles and the impact that these could have on the results. Conway and Christiansen (2005) found the auditory channel to afford better learning, among the modality effects they researched. The modality effect in learners is something for which this study did not control. The fourth delimitation of this study was that given the use of retrospective data from a formal training course in a company, it was not possible to perform an experiment to obtain comparative results of the effects of multimedia elements.

\section{Definitions and Terms}

The following terms and definitions were used throughout this study. There are several terms that can be used exchangeably throughout literature due to their nature of technological meaning. Therefore, those terms are defined below for consistency.

E-Learning: Short for electronic learning, which generally involves information technology, especially the Internet. This format of learning is comprised of multimedia learning material that ranges from audio to video to text to discussion boards and other learning tools (Romanov \& Nevgi, 2007).

Multimedia: More than one medium of communication can be used to communicate a message. The term multimedia may combine any of the following: (a) video, (b) sound, (c) graphics, (d) animation, (e) still photography or (f) text (Kanning, 1994).

Learning Effectiveness: Measurement of learning that has an impact or effect in performance at the organizational level. Includes goals, strategies, policies and routines that employees have to be aware of and perform on a regular basis (Fuglseth \& Gronhaug, 2003). 
Learner Satisfaction: An indicator of learners wanting to participate more, demonstrate greater learning gains, and overall be more inclined to seek online content in corporate learning (Gunawardena et al., 2010).

MP3: Digital music format that contains high quality sound files. This file format has the ability to compress large files, which makes them convenient to download, email, and store in learning management systems or portable devices (Stucken, 2010).

FLV: Media format developed by Macromedia later acquired by Adobe Systems. The format allows for delivery of synchronized audio and video content in a streaming format. The streaming content allows users to begin watching and listening to a multimedia file before it is completely downloaded to the computer's memory (Adobe, 2010).

MP4: Name commonly used when referring to video media file used to play back high quality videos. Video files with high compression and high quality contain the file extension .mpg4 or .mp4 (Farthing, 2012).

DRM: Digital Rights Management, a technology developed and adopted voluntarily by content owners to protect the mixing, copying, burning, or ripping of multimedia content (Mulligan, 2003).

\section{Organization of the Study}

This chapter includes the introduction and background to the problem, purpose statement, research questions, and theoretical framework. The significance of the study, assumptions and delimitations, and definitions of terms were also discussed. Chapter two provides a review of the literature supporting the study. Chapter three describes the research method proposed to conduct the study. Chapter four reports the results from the 
statistical analyses, and chapter five provides a discussion of findings and implications for research, academia, and practice. 


\section{CHAPTER II}

\section{LITERATURE REVIEW}

The following literature review provides a framework that includes the most salient topics relevant for this study. The first section of this chapter reviews literature that supports the use of multimedia elements such as video and audio in e-learning courses. The second section examines two theories that support the use of multimedia in e-Learning; these theories are: (a) generative theory of multimedia learning, and (b) cognitive theory of multimedia. The third section of this chapter addresses the effectiveness of learning as well as the measures of satisfaction used in the workplace.

\section{Multimedia in e-Learning}

Early online courses delivered content via text and images on learning management systems, such as Blackboard. Subsequent available technologies allowed the use of various multimedia elements. Driscoll (2002) asserted that using multimedia elements can reduce the effort required to convey a message. Courses now emulate the latest podcasts (Diezmann, C. \& Watters, J. 2002; Bolliger et al., 2010) as found in Apple's iTunes (Meister, 2009), and courses that include video content such as that of YouTube (McNeill, 2008). Some courses also include animation and interactive animation similar to those found in video games. Users embrace the podcast format of online course lectures because they consume commercial music in that format (Bolliger et al., 2010). 
The podcast format gives the student a sense of familiarity over technology and functionality. Researchers have found that students who watch video clips as part of online courses achieve higher course grades (Romanov \& Nevgi, 2007). Researchers have also uncovered a positive correlation between the assessment scores and learners who watched videos in an e-Learning course $(r=0.35, p<0.01)$ (Romanov \& Nevgi, 2007). Hirumi et al., (2010) found that multimedia, specifically video game interaction, motivated learners to increase their social interaction. In contrast to an academic setting, learners in the workplace do not necessarily have the same incentives such as grades or a degree; instead, they have different motivations for learning.

Motivations range from fulfillment of their organization's requirements for employment, their leader or manager's expectations, or acquisition of a skill that is necessary to complete a task required in a specific role. Learners in the workplace often strive for performance-oriented learning connected to their specific work tasks (Wang et al., 2010). One consideration researchers often take into account is that the audience of learners found in the workplace may not be different than the audience of learners in academia. This similarity is due to the fact that a higher number of non-traditional students in academic institutions are currently in a workplace, hence the phrase nontraditional student. Therefore, learners in both environments expect more updated technology and multimedia during their learning experience.

Learners taking part of e-Learning experiences are expecting these multimedia elements to be more prevalent in courses. The more pressing questions arising from this expectation of robust multimedia are its effectiveness and the learner satisfaction in online courses that contain multimedia. According to several scholars (e.g., Brown, 
Kirkpatrick \& Wrisley, 2003; Tagg \&Arreola, 1996; Carlton \& Ryan, 1998), video components are found more often in online courses. The use of video as a multimedia element in an online course provides an additional mode of inter-human communication where the participant can perceive the body language of the instructor in conjunction with their spoken words during a lecture (Pullen, 2001).

In addition, Diezmann and Watters (2002) found that the generative and dual coding theories elaborated by Mayer (1997) have a meaningful learning impact in a multimedia environment. For example, learners select words and images from the presented material to organize coherent mental representations of the content presented; hence the visual images contribute to providing richer learning experiences by being a complement to the printed content. As a result, course developers and designers have to ponder the benefit of investing the time, money and effort to incorporate multimedia elements into their courses, due to student's expectations of more elaborated multimedia and higher fidelity video (Choi \& Johnson, 2005). Incorporating multimedia elements into online courses may generate e-Learning effectiveness and learner satisfaction. Furthermore, course developers and designers should consider the modality effect of multimedia in the learners' cognitive load.

The modality effect refers to the way in which content is presented (e.g. text, audio, graphics, etc.). Guan (2009) found that learners exposed to an online course with multimedia elements lasting an hour or more demonstrated a negative impact on learning. Therefore, course developers must be mindful of the length of any multimedia elements in online courses, minimizing their duration. These findings should encourage course developers to avoid using only text or only audio for presenting content that may be 
lengthy in nature and, most importantly, not include long pieces of multimedia. Course developers can also take advantage of video as another element of multimedia to apply the modality effect.

\section{Video}

Video is a media element that has evolved with technology. During the early days of the 1970's, television stations produced video signals using 29 frames per second. The only channels used to transmit video signals were located in the Ultra High Frequency (UHF) and Very High Frequency (VHF). These frequencies were transmitted for Low Power Television sets (LPTF) (Barthold, 2001). The video signals sent in either of these frequencies were considered analog and did not allow for compression of the signal. As technology and the Internet evolved, video signals became more sophisticated. The use of encoding software allowed reducing the size of video signals. The use of encoding software gave way to the use of video formats such as MPEG, FLV and recently MP4 (Herzog, 2008).

These video file extensions are indicators of the amount of compression and file reduction of video. The newer compression formats facilitate the inclusion of video in many online course outlines. Companies such as Adobe use high technology software to assist course developers in the inclusion of video in online courses. Videos in MP4 encoding format are another way course developers can include them in e-Learning, while maintaining low file size and efficient stream of the video. Guan (2009) found a small insignificant difference in performance between learners presented with static images content (mean $=6.429, S E=0.504$ ) and those who were presented with animated content (mean=5.445, $S E=0.637$ ). Although video encoding formats permit smaller file 
size, a way to leverage small storage space is to create audio files, which take a fraction of space in comparison to video files.

\section{Audio}

Many learners are auditory learners, and in many cases they do not find text "chat" as a good substitute for spoken words (Pullen, 2001). Audio is a multimedia element present in online learning to help auditory learners acquire knowledge. The most common digital audio format is the WAV file, created by Microsoft and IBM (Lau, 2007). This audio format is the most common for the personal computer. However, due to its lossless structure or fact that it is the most complete file format, its file size is not suitable to e-mail or include in online content. This format takes too long to transfer over the Internet because of its complex structure and amount of information.

The next file format for audio is the MPG-1 Audio Layer 3 or MP3 for short. Audio files compressed in MP3 format are about $1 / 10^{\text {th }}$ the size of a WAV file (Lau, 2007). In many cases MP3 appears to be the most common audio format used. MP3 audio format became the standard once the audio players were branded MP3 players. The main reason to use MP3 is for reducing the file size of audio files and also maintaining a high quality. Microsoft launched WMA or Windows Media Audio at the same time that MP3 file format was becoming popular (Lau, 2007). Microsoft claims to have achieved three times more compression than an MP3 file. Course developers can consider MP3 and WMA as viable audio formats to use for learning in online courses, given their compression and good quality claims.

The only consideration when developing online courses using audio files is the software platform. WMA files may offer a higher compression rate while sustaining the 
audio quality; however these files require Windows Media Player found exclusively in Windows based computers, regardless of the Internet connection. Learners with computers running a different operating system other than Windows would not be able to listen to audio files encoded in WMA format. However, virtually any computer with any operating system is capable of playing MP3 file format, making this audio format ideal for audio content in online courses, and due to its compression size it is a good substitute for video files when files size is of the essence. As course developers determine which file formats are suitable for video, audio and images, they also should consider the financial cost of creating e-Learning based on time of development. Driscoll (2002) used the standard one hour of content to measure hours needed to develop the corresponding eLearning module. For every one hour of e-Learning containing multimedia, the estimate is 490 hours for soft skills and 480 hours for technical skills (Driscoll, 2002). See Table 1 for estimated development hours of e-Learning courses.

Table 1

Estimate of Hours Needed to Develop One Hour of Web-Based Training. Driscoll (2002)

Estimates from WBT Practitioners in 2001

\begin{tabular}{lcc}
\hline Production Quality & $\begin{array}{c}\text { Soft } \\
\text { Skills }\end{array}$ & $\begin{array}{c}\text { Technical } \\
\text { Skills }\end{array}$ \\
\hline $\begin{array}{l}\text { Basic I } \\
\text { Basic linear presentation, limited interaction, and simple } \\
\text { media }\end{array}$ & 90 & 100 \\
Medium II & & \\
$\begin{array}{l}\text { Moderate levels of interaction, rich media, and moderate } \\
\text { nonlinear branching }\end{array}$ & 170 & 190 \\
$\begin{array}{l}\text { High III } \\
\text { Highly interactive program using rich media and complex } \\
\text { nonlinear branching }\end{array}$ & 490 & 480 \\
\hline
\end{tabular}


The cost of development of e-Learning varies depending on the amount of components needed. Course developers cost range from $\$ 65$ to $\$ 100$ per hour (Driscoll, 2002). See Table 2 for the cost per hour of each task that can be considered for online courses.

Table 2

The going rate. Driscoll (2002)

\begin{tabular}{ll}
\hline Instructional technologist & $\$ 65$ to $\$ 100$ per hour \\
Instructional designer & $\$ 75$ to $\$ 100$ per hour \\
Writer/editor & $\$ 40$ to $\$ 65$ per hour \\
Graphic artist & $\$ 35$ to $\$ 65$ per hour \\
Programmer/authoring specialist & $\$ 30$ to $\$ 65$ per hour \\
Java/CGI programmer & $\$ 85$ to $\$ 120$ per hour \\
Media expert & $\$ 65$ to $\$ 120$ per hour
\end{tabular}

Course developers faced with estimates of time and cost can leverage the use of multimedia with newer technology. An example of technology changes that influence cost and time estimation include: (a) video production, (b) equipment for video capture, . and (c) the software needed to edit video, these technologies are inexpensive and more intuitive now that in previous years. The same can be considered for audio production and its cost. Therefore, it is less expensive to produce multimedia for online courses and the time to produce multimedia content can potentially be less as well. 


\section{Multimedia Learning Theory}

Clark and Mayer (2008) found that learners engage many times, in much essential processing resulting in overload of the cognitive system. Such overload is due to the attention learners must direct to multiple pieces of content presented in a lesson. Mayer and Moreno (2003) listed three cognitive demands that a learner may encounter causing a cognitive overload. These are: (a) essential processing, (b) incidental processing, and (c) representational holding.

Essential processing in cognition involves making basic sense of the material presented (Mayer \& Moreno, 2003). For example, when presented with unfamiliar content in a fast paced manner, the learner must invest a great deal of cognitive processing capacity to select relevant concepts from the unfamiliar content and organize the information to integrate the new information with prior knowledge (Mayer \& Moreno, 2003).

Incidental processing is a cognition task the learner will encounter when learning material is presented. Some of this processing takes place when the learner encounters additional information, side information or reference information that is not directly necessary to process the materials at hand, hence the term incidental.

Representational holding is described by Mayer and Moreno (2008) as the cognitive process of retaining recent information in working memory over a period of time. The concept is to integrate all information acquired and retained it in short term memory to generate knowledge to complete tasks. 
Multimedia serves another effective purpose in online courses to reduce cognitive load when course developers use multimedia to create pre-training components. Sometimes course content that is too extensive can overwhelm learners, especially when they must consume it all during one single session. Clark and Mayer (2008) suggest reducing the size of learning content by using multimedia to create small segments for pre-training. Course developers can take advantage of this practice to reduce the amount of time learners must be away from their normal tasks to begin loading knowledge into short term memory for later integration with other concepts. The use of multimedia in the form of podcasts and video capsules provides an effective and relatively flexible platform to distribute pre-training content (Clark and Mayer, 2008).

\section{Generative Theory of Multimedia Learning}

Mayer (1997) describes how learners are presented with newer technology and yet a less than equivalent advancement of understanding how people absorb knowledge. Mayer (1997) draws from a generative process of comprehension presented by Wittrock (1990) and Paivio's dual coding theory. Using these two theories, Mayer was able to form the generative theory of multimedia learning stating that learners select, organize and interpret information included in an online course with multimedia.

Mayer (1997) explains the integration of multimedia in the learning process to generate knowledge in a similar format as encyclopedias. An encyclopedia generally presents a block of text describing a process or an artifact, and shortly thereafter is an illustration of the process and how the artifact functions. Learners have the ability to absorb the content of the written text and in some cases the narration as well as the visual information (sometimes in forms of illustrations or animation). The combination of 
written text or narration combined with visuals is referred as multimedia learning experiences, which carry a cognitive consequence of multimedia learning when the information is organized and stored in working memory for later integration or use. Paviov (1986) presents the dual coding theory which highlights the presence of two channels, one which contains the verbal stimuli that activates the verbal representation and the other channel that contains the visual stimuli, which activates the construction of a visual representation (Mayer, 1997). The generative theory of multimedia is derived from the generative process of comprehension presented by Wittrock (1990). The following sections present both the generative process of comprehension and the dual code theory.

\section{Generative Process of Comprehension}

The generative theory cited by Mayer (1997) is derived from the generative process of comprehension presented by Wittrock (1990). The process of comprehension shifted the interest from the environments that influence learning to the way learners use background knowledge and thought process to construct meaning. Learners take verbal elaborations and imagery to construct meaning. For this process, Wittrock (1990) describes how learners construct meaning from stimuli and knowledge from experience by attending, selecting, and constructing meaning.

The generative process of comprehension is heavily focused on the reading and writing activities. Writing is the process of putting meaning on written pages, and reading is the process of getting meaning from the written pages (Wittrock, 1990). One can consider writing as a constructive or generative skill as it is the active process of 
recording meaning. However, reading is merely a reproductive or imitative skill taken from the written text.

Wittrock (1990) proposes that both writing and reading involve a generative process by building relations. Learners build relations among the parts of the text, and also between the text and what one knows, believe and experiences. The action of writing promotes the generation of meaning by relating knowledge and experiences to text. The generative process is evident in learners when they are presented with text and relate it with experiences and previously acquired knowledge stored in long term memory. Therefore, as the generative process of comprehension relies on both writing and reading, when adding audio, learners use two input channels to absorb information, also referred as dual code theory.

\section{Dual Code Theory}

Learners have two input channels, the visual and the aural. These channels represent the verbal and non-verbal representation (Welcome et al., 2011). Paivio (1986) indicates that cognitive processes take place within two separate processing systems or channels, the visual system for processing visual knowledge, and the verbal system for processing verbal knowledge. The visual system is tasked with two functions, to capture the written text and also to capture the visual imagery related to a concept. Likewise, the verbal system is tasked to capture narrated text as well as descriptive narration. Welcome, Paivio, McRae and Joanisee (2011) describe the verbal and non-verbal systems performing functions of the other as referential interaction between verbal and non-verbal representations. 
Another component of the dual code theory is the concrete and abstract representations for verbal and non-verbal content. A learner can concretize an abstract term by referencing its associate term. Learners can also generate mental images for abstract items or concepts by retrieving situational knowledge associated with the concept (Welcome et al., 2011). The activity of referential interaction between the channels presented in the dual code theory, transfer to the generative theory of multimedia learning. Verbal and non-verbal representations are processed by learners; this creates a text base and an image base. Each base is organized by words and images respectively, to create verbally based and visually based models. Both verbal and visual models are then integrated for the knowledge acquisition to be complete.

Schwamborn, Thillmann, Opfermann and Leutner (2011) found multimedia to be a generation condition that did not differ on prior knowledge, spatial ability or verbal ability $(p<.001)$. However, multimedia appeared to require more learning time $(p<.05)$ for the learner to generate knowledge. Researchers mentioned two conditions related to learners knowledge generation activities with multimedia, (a) learners generate information more effectively when presented with multimedia $(p<.05)$ because the activity corresponds to a near transfer event speaking of the mental processing and the long term memory information recalling process, and (b) learners take longer to generate knowledge when presented with multimedia only because learners' non-familiarity of the media.

Plass, Chun, Mayer, and Leutner (2003) found multimedia to support knowledge generations for high-ability learners. Researchers considered spatial, verbal and visual abilities in learners. Their analysis showed a significant interaction of verbal and visual 
abilities $(p<.05)$ and a significant interaction of spatial, verbal and visual abilities $(p<$ .001). Plass et al., (2003) concluded the generative theory of multimedia learning is accurate in describing that learners have more knowledge acquisition when both visual and verbal annotations, such as images and audio, are present in a multimedia course.

\section{Cognitive Theory of Multimedia Learning}

Similar to the generative theory, the cognitive theory of multimedia learning relies on the dual code theory by acknowledging two channels. Multimedia can contain written text, spoken text, visual images, animation, or a combination of all. Moreno and Mayer (2000) present a cognitive theory of multimedia learning model that relies on three types of memory: (a) sensory memory, (b) working memory, and (c) long-term memory. The last component of this theory is the prior knowledge or experiences stored in long-term memory by the learner.

The model accounts for the multimedia presentation to include verbal and nonverbal representations. Sensory memory is activated and verbal representations enter through the learners' ears. Non-verbal representations enter through the learners' eyes. During this process, sensory memory selects words and images, and images in turn are transferred to working memory. Learners' working memory takes the verbal and nonverbal representations and organizes both to create verbal and pictorial mental models. This model describes the use of knowledge previously stored in long-term memory, and it is recalled to become integrated with the verbal and pictorial mental models integrated in working memory (Moreno \& Mayer, 2000).

The cognitive theory of multimedia learning draws from the same models as the generative theory in that both rely on dual code theory to account for verbal and non- 
verbal representations. Both theories suggest the processing of verbal and non-verbal representations by organizing words and images. Last, both theories suggest the integration of selected representations previously organized. The two main differences between each of these theories are that the cognitive theory of multimedia learning includes: (a) the designation of sensory, working, and long-term memories for staging areas for the selection, organization, and application steps to occur, and (b) the integration of prior knowledge stored in long-term memory.

Schwamborn et al. (2011) found multimedia provided for higher retention of knowledge by learners $(p<.05)$. Researchers' statistical findings supported the cognitive theory of multimedia, stating pictures embedded in learning courses facilitated the transfer and retention of information. In addition the inclusion of pictures in online courses reduced mental effort $(M=4.20, S D=1.59)$ (Schwamborn et al., 2011). Jones and Plass (2002) also found learners presented with multimedia elements such as pictures and audio in a course reported statistically significant differences. Learners with no multimedia elements performed lower $(N=42, M=8.10, S D=4.3, p<.001)$, and learners with both multimedia elements performed higher $(N=44, M=19.75, S D=3.2$, $p<.05)$.

Austin (2009) conducted a number of experiments that included multimedia elements such as static text, animated text, and narration in an online course. The researcher examined the role of multimedia combination on transfer learning. The experiment considered the following combinations of multimedia elements: (a) AN: animation and narration, (b) AT: animation and text, and (c) ANT: animation, narration and text. Austin found animation and narration produced higher scores than animation 
and text alone $(t(48)=3.95, p<.001, d=1.12, r=.49)$. Austin (2009) further explored the effects of multimedia. He found modality and redundancy of multimedia elements had an impact on effectiveness recorded with test scores. The researcher asserted the benefit of using multimedia elements; however, Austin (2009) suggested further examining the effectiveness of e-Learning courses with multimedia elements.

\section{Learner Effectiveness}

Employee effectiveness can be observed in various ways including observations, formative and summative evaluations of tasks, as well as knowledge transfer and retention via online tests. However, there are other indicators of effectiveness in eLearning. Schillings (2009) documented the following indicators of effective online learning: (a) online community, (b) grades, and (c) meaning. Palloff and Pratt (2001) found that students who are a part of an effective online community have the characteristics of: (a) support, (b) sharing, and (c) encouragement between students. Githens (2006) also found that incorporating interpersonal interaction in online courses at the workplace has a positive relationship between increased interpersonal interaction and success in computer-based learning. Students' grades on individual assignments and the overall course are positive indicators of effective online learning. Even though scores are also direct indicators of effective traditional classroom learning, they constantly indicate acceptable performance in the learning process of a student regardless of the medium (i.e., classroom versus online), based on the instructional design model (Driscoll, 2002). Students tend to perceive learning in a positive and effective way when they do not have the sense of isolation in online environments. As students develop a sense of community, 
their quality of online discussions seems to increase, and as a result student persistence is also more pronounced.

Fuglseth and Gronhaug (2003) found that it is difficult to measure organizational learning. They explained that measurement of employee learning is necessary in order to indicate whether learning is taking place, and further find any impact or effect in performance at the organizational level. Employee learning in an organization can be considered effective when its measure is matched to organizational references (Fuglseth \& Gronhaug, 2003). The organizational references are elements such as goals, strategies, policies, and routines that employees have to be aware of and perform on a regular basis. Although these organizational references can be established, it is necessary to resource to learning events that can continue to enhance knowledge around the goals, strategies, policies, and routines (Fuglseth \& Gronhaug, 2003).

The four elements of organizational references have key performance indicators to measure the effectiveness. Wang, Ran, Liao, and Yang (2010) described a set of key performance indicators (KPIs) that focus on organizational and individual performance. The identification of KPIs provides a clear image of what is important for the organization, what employees need to do and learn to support the organizational goal. Such framework of KPIs is synonym of performance oriented system design as it is comprised of three levels: (a) the organizational level, (b) the business unit level, and (c) the position or role level (Wang et.al, 2010). Each of the levels has a specific framework based on the components of the levels. When looking at the framework for the position or role level, the KPIs are set by capability or competency. Each in turn has a rating 
criterion, which generally can be based on the level of knowledge or performance. The rating is calculated based on the level of knowledge or performance (see Table 3).

Table 3

A KPI Framework at the Position/Role Level. Wang et. al. (2010)

\begin{tabular}{|l|l|l|l|l|}
\hline Employee ID & Position/Role & KPI Item (capability) & Rating Criterion & \multicolumn{1}{|c|}{ KPI Value (Assessment } \\
Result)
\end{tabular}

The KPI framework for a position or role provides context to the assessment of effectiveness of a training event in a company. The training will provide either a change of behavior or reactions to performance in a given situation. Therefore, the use of a KPI framework is an effective way to measure effectiveness of online learning in the workplace. In order to determine or establish the effectiveness of training in an organization, there needs to be a diagnosis process that determines how employees' work can be enhanced. Once that diagnosis has yielded results, it is then possible to establish the need for training, plan the training and the evaluation of its effectiveness (Ley \& Alberts, 2003).

Effective learning is often a synonym of meaningful learning (Schilling, 2009). Meaningful learning increases when visual and verbal content are added to online courses. Hence the use of multimedia elements such as video and audio, in addition to traditional text and images, becomes more important when designing learning content to be delivered in online courses. Choi and Johnson (2005) found qualitative measures that 
indicated that learners perceived that video-based instruction was more memorable than text-based instruction. Attention is an influence on motivation for learners' performance, the study found significant difference in learners' attention between video-based learning and text-based learning $(p<.05)$ (Choi \& Johnson, 2005). Furthermore, the researchers found that video-based learning accounted for higher levels of understanding $(p<.05)$. No other studies have been found in the literature that examines the effectiveness of multimedia in e-Learning. However, learner satisfaction with e-Learning courses needs to be reviewed to consider measuring learner satisfaction with e-Learning courses that contain multimedia.

\section{Learner Satisfaction}

Several researchers have indicated that learner satisfaction is influenced by multimedia elements included in e-Learning (Lei \& Gupta, 2010; Liaw, 2008; Morgan, 2007; Rodriguez, Ooms \& Montañez, 2008). Gunawardena et al. (2010) found that learner satisfaction was an indicator of learners wanting to participate more, demonstrate greater learning gains, and seek more online content in corporate learning. One of the independent variables the researchers identified to measure learner satisfaction is learner online self-efficacy (Gunawardena et al., 2010). Rodriguez et al. (2008) also found that learners' comfort with using the Internet was considered a related factor to learner satisfaction. The use of multimedia in online courses can be beneficial for the learner, as online self-efficacy does not need to be extremely high in order for the learner to interact with the multimedia. Although none of the research cited a direct correlation between multimedia and satisfaction, the overall sense is that learner self-efficacy to use a 
computer and access the Internet is a key factor (Lei, Gupta, 2010; Rodriguez et al., 2008).

Gunawardena et al. (2010) suggested four independent variables to measure learner satisfaction on an e-Learning course: (a) online self-efficacy, (b) course design, (c) learner-learner interaction, and (d) learner-instructor interaction. The research indicated that 88 percent of the variance in learner satisfaction was attributed to the four independent variables $\left(R^{2}=884\right)$. The highest predictor of learner satisfaction was online self-efficacy with 63 percent of the variance. Course design accounted for 14 percent of the variance, and the researcher did not specifically indicate whether multimedia was an element of course design.

Choi and Johnson (2005) stated the learner's motivation will increase with video based instruction that provides attention, relevance, confidence, and satisfaction. The ARCS (attention, relevance, confidence, and satisfaction) model of motivation cited by Choi and Johnson (2005) is a relevant model to consider when creating e-Learning content containing multimedia. The ARCS model supports the premise that the learner will be motivated to have a successful learning experience and hence choose to seek more learning resources with similar multimedia format such as video and audio. Choi and Johnson (2005) collected data with a Likert-scaled instrument, and used a paired $t$ test to measure the mean of learners' motivation when presented with video-based instruction. The researchers found learners' attention mean statistically significant $(p<.05)$; however, relevance and confidence were not statistically significant (relevance: $p>.05$ and confidence: $p>.05$ ). And even though satisfaction was not statistically significant, 
the value $(p>.05)$ is something relevant to further explore considering that the researchers obtained this result as an exploratory study.

Liaw (2008) found a correlation between behavioral intention and perceived satisfaction and usefulness of e-Learning. The correlation of perceived satisfaction and behavioral intention was high $(r=0.72)$ as well as that of usefulness of e-Learning and behavioral intention $(r=0.76)$ which indicates that there is value in incorporating multimedia in e-Learning to enhance its usefulness and perceived satisfaction.

\section{Summary}

Multimedia is a key component of online course development. Considering ongoing technological advancements it is important to pay close attention to the effect multimedia has on learners' effectiveness and satisfaction. The evolution of technology and increase of bandwidth, paired with the newer ways to use learning platforms, forces course developers to be more vigilant of the type of multimedia needed to make a course effective and satisfactory for learners.

Online learning can be more effective and satisfactory when the generative and cognitive theories of multimedia learning are taken into consideration. Dual code theory is essential when developing online courses. Even though it is important to account for both verbal and non-verbal channels, it is also relevant to keep in mind the balance of these channels to avoid the cognitive overload.

Little research has examined the use of multimedia elements in online courses.

While some studies found the use of multimedia advantageous in online courses, research does not account for duration in length of multimedia elements in an online course. 
This chapter examined the literature surrounding Multimedia including an introduction and examination of scholarly perspectives. Literature included, multimedia elements, generative theory of multimedia learning, cognitive theory of multimedia, learner effectives, and learner satisfaction. Chapter 3 discusses the method proposed for this study. 


\section{CHAPTER III}

\section{METHOD}

This chapter reviewed the purpose of the study and the research questions. It described the research design, the variables considered for this study, the data gathering, and the analysis techniques to answer the research questions in this study. A summary of the method with an outline of relevant points is included at the end of this chapter.

\section{Purpose of the Study}

The purpose of this study was to determine how the use of multimedia components, such as animation, audio, and video, in online courses was related to perceived learner satisfaction and learning effectiveness.

\section{Research Questions and Hypotheses}

Two research questions guided this proposed study: (a) is there a relationship between learners' perceived satisfaction of a course and the use of graphics, audio, narration properly synchronized with the text animation, and video in the course? (b)

does the reason for enrolling in a course predict the learner score of an online course that contains multimedia? To explore these research questions, five hypotheses were proposed for examination:

$H_{l}$ : There is a positive relation between learners' objective performance and satisfaction with the use of graphics in an online course.

$H_{2}$ : There is a positive relation between learners' objective performance and perceived satisfaction with the use of audio in the course. 
$H_{3}$ : There is a positive relation between learners' objective performance and perceived satisfaction with the narration properly synchronized with the text animation of the course.

$H_{4}$ : There is a positive relation between learners' objective performance and perceived satisfaction with video used in the course.

$H_{5}$ : After controlling for learners' perceived satisfaction with the use of graphics, learners' perceived satisfaction with the use of audio, learners' perceived satisfaction with the use of narration properly synchronized with text animation and learners' perceived satisfaction with the use of video, the reason for enrolling in the course will predict learners' performance.

\section{Research Design}

This research was non-experimental. Vogt and Johnson (2011) defined nonexperimental as a design approach where the researcher does not control the independent variables, and does not assign subjects to treatment. For the purpose of this research, all data was considered retrospective and preexisting. Boslaugh (2007) suggested that when data is collected by someone other than the researcher or for some other purpose other than the explicit use of data in research, data is considered secondary data. The data source for this research is a secondary data source as no first-hand data was collected for this study. All retrospective data was related to results for the same e-Learning course, and was collected during a full calendar year.

\section{Population and Sample Size}

The target population for this study consisted of employees who have responsibility within the Medicare unit in a large, multinational, publicly traded 
healthcare company. The Medicare unit included areas such as product design, risk adjustment, network operations, and actuaries. Employees ranged from front-line level to mid-level management of a variety of departments specific to the segment of Medicare operations. In addition to employees from the Medicare operations area, employees from other areas across the organization were self-identified as the target audience. The topic of the e-Learning course was Medicare general knowledge. The purpose of the course was to provide a baseline of knowledge about Medicare for all employees primarily of the Medicare operations area. Even so the course was available for employees from any other area outside of the Medicare area who sought to learn more about the basic principles of Medicare. In total, the resulting population registered for this course in 2012 was 5250 employees.

In regards to sample size, Green (1991) indicated that for methods such as multiple regression, it is recommended to have a sample size of at least five and up to 50 participants per variable. The sample size for this secondary data was 2,401 (representing a $48 \%$ sample of the total population: $N=5,250)$; this number was representative of the total number of employees that completed the course in its entirety and earned a score as well as those who completed the resulting satisfaction survey. All 2,401 respondents met these criteria. As such, the retrospective data set was adequate for testing the proposed hypotheses with appropriate statistical strength. The probability of type II error was small considering the large sample size (Hinkle et al., 2006). To guard against the potential for inflated measurement error due to the large sample size, the researcher examined the variance inflation factor (VIF) for issues of multicollinearity. 


\section{Variables and Instrumentation}

The following section presents the multimedia components included in this research. First, multimedia will be discussed, followed by each of the multimedia components. Each component was addressed by one question in the survey. The individual scores for each multimedia component were examined for significance. The instrument's description follows, and a full version of the instrument can be found in Appendix A.

\section{Multimedia}

Multimedia is comprised of any presentation that contains words, such as narration or onscreen text, graphics, photos, animations or video (Clark \& Mayer, 2008). In early days of online course development, learners experienced only a set of the elements of multimedia such as text and images. At the time video, audio and animation components were not convenient to include in e-Learning given their original file size. Multimedia platforms were in their infancy of limited capacity for file sizes (Yvas et al., 2010), and video and audio formats were very specific in terms of the software that could play each of the formats.

Video. With the advent of video signals in digital format, course developers started to consider using video files to complement course content. In the early use of multimedia, video could be produced using a variety of file formats (Herzog, 2008). Course developers began to leverage the technology advancements in multimedia platforms such as YouTube (Kekkonne-Moneta \& Moneta, 2002). The general use of YouTube and development of more software, nimble in file format playback function, made the common video formats those like MP4 and FLV (Farthing, 2012). Video files 
in the Medicare course were used in MP4 format. The term video in this course was operationalized as video containing audio, animation, and a combination of images that alternated in sequence according to the content presented within the FLV file format. The Medicare course observed for this study used four video files in FLV format, and each video file was presented in separate modules of the course. All video files were repurposed from their original intent for this course, therefore there was no direct cost associated with the creation of these videos. Each video presented navigation controls independent of the course navigation. This allowed learners to start and stop the video and modify the volume as necessary. In this study, video satisfaction was measured by survey item 15 of the instrument. The measure used in this study for video was, "The video format aided in my understanding of the subject matter."

Audio. Audio is a multimedia element present in online learning to help auditory learners acquire knowledge. The most common digital audio format is the WAV file, created by Microsoft and IBM (Lau, 2007). This audio format is the most common for the personal computer. Another file format for audio is the MPG-1 Audio Layer 3 or MP3 for short. Audio files compressed in MP3 format are about $1 / 10^{\text {th }}$ the size of a WAV file (Lau, 2007). The availability of this type of media provides learners with more choices and accommodates individual differences such as preferences and learning styles (Bolliger et al., 2010). The Medicare course observed for this study used audio files in MP3 format throughout the course. Course developers used internal talent to create the audio files, and the only cost considered for these audio files included the cost associated with the course developer's time. Refer to Tables one and two of chapter one for an estimated cost of course developer or instructional technologists' estimated rate for 
development. Audio satisfaction was measured by items 16 and 17 of the instrument. A sample item used to measure audio in this study was, "The audio for the narration was clear. (If applicable)."

Graphics. The use of pictures, graphics, tables and diagrams is an important instrument in e-Learning for getting learners' attention and provide an effective experience (Jereb \& Smitek, 2006). Learners benefit by having content presented in media that uses the dual coding channel format (Jereb \& Smitek, 2006). The use of graphics with text or graphics and audio provide information that requires the learner to use two channels to capture information, reducing the cognitive load (Jereb \& Smitek, 2006). The Medicare course observed for this study used images depicting office settings and cartoon-like characters throughout the course. The course developer used basic clip art, which allowed the developer the option to change colors, gestures, and character positions to represent various scenarios throughout the course. The associated cost for graphic generation is limited to the graphic artist or instructional technologist rate included on Table 2 found in chapter one. The use of graphics satisfaction was measured with item 14 of the instrument. The item used to measure this variable in the study was, "There was an appropriate use of graphics throughout the CBT."

\section{Instrument}

The instrument proposed for use in this study was developed in 2008. Dillman's tailored design method was utilized in the development of the instrument. The following steps were adhered to ensure adequate survey design. See Table 4. 
Table 4

Steps completed in Dillman et al.'s (2009) tailored design method

\begin{tabular}{|c|c|}
\hline Steps & Purpose of Step \\
\hline 1. Survey content reviewed by & This step is designed to draw suggestions \\
\hline \multirow[t]{2}{*}{ knowledgeable colleagues and analysts } & on research content by those who have \\
\hline & created other surveys. \\
\hline 2. Conduct interviews to evaluate cognitive & Step two allows for the test of \\
\hline \multirow[t]{2}{*}{ and motivational qualities of content } & appropriateness of questions, order, and \\
\hline & delivery method working as intended. \\
\hline \multirow[t]{2}{*}{ 3. Conduct a small pilot study } & This step is designed to execute the \\
\hline & procedures that will be used for the study \\
\hline \multirow[t]{5}{*}{ 4. Do a final check } & This step elicits the final review and \\
\hline & finalizes any changes and account for \\
\hline & opinions from someone not involved in the \\
\hline & study to review the instrument for missing \\
\hline & information. \\
\hline
\end{tabular}

The group of instructional designers who worked to develop the survey for use in this study included a learning analyst, responsible for extracting and interpreting the data, two instructional designers focused primarily on the design of stand-up training materials, two instructional technologists, responsible for the development of online courses, and the learning manager who approved the use of the instrument designed. The first step included the learning consultants and instructional technologists identifying a list of factors that were going to be considered in measuring learner satisfaction in online 
courses. The team selected from a pool of existing questions to create a draft of the instrument. Second, the team conducted an agreement meeting that included the designers and technologists as well as the analyst and the learning manager.

The team received approval from the learning manager to utilize the instrument in pilot. The pilot helped test the instrument length, question order, question syntax, instrument use in the learning management system and the learner's ability to complete the instrument without hindering the course completion process.

To complete the final step, the learning team reviewed the data collected from the pilot. As a result of the pilot, three questions were modified to include words of increased satisfaction (i.e. included "agree" and "strongly agree" and "disagree" or "strongly disagree"). Additionally, the learning team found that some learners would respond straight-through all questions. The team reversed one question to identify those straightthrough responses and remove them from the overall analysis.

The instrument was comprised of 25 questions. Eighteen questions used a five point Likert-scale. Four questions elicited qualitative feedback, and three questions collected demographic data. Table 5 shows the anchor points and the coding for each. Table 5

Agreement five-point Likert-scale used in the SPLD- Survey

\begin{tabular}{lc}
\hline \multicolumn{1}{c}{ Anchor point } & Code value \\
\hline Strongly Disagree & 1 \\
Disagree & 2 \\
Neutral & 3 \\
Agree & 4 \\
Strongly Agree & 5 \\
\hline
\end{tabular}

The survey was uploaded to the Learning Management System (LMS) and added to the Medicare 101 course outline. Every employee is introduced to the interface of the 
LMS as a part of their onboarding. All learners had awareness of the steps necessary to open the satisfaction survey included in the course outline. Therefore, no additional instructions were added to the beginning of the survey. The LMS displayed the survey with radio buttons for each anchor point of the agreement scale. All 25 questions were displayed in one page. Learners responded to all question items and subsequently clicked the button labeled "Submit answers for scoring" for their answers to be recorded. Next, learners were to click a button located on the bottom left part of the screen labeled "Return," and the button took learners back to the course outline to mark the course complete. For this study, questions shown on Table 6 were used to run the statistical analyses to accept or reject the null hypotheses. 
Table 6

Questions used to conduct hypotheses tests

\begin{tabular}{|c|c|c|}
\hline Question \# & Question & Hypothesis \\
\hline 14 & $\begin{array}{l}\text { There was an } \\
\text { appropriate use of } \\
\text { graphics throughout the } \\
\text { CBT. }\end{array}$ & $\begin{array}{l}H_{1}: \text { There is a positive relation between } \\
\text { learners'objective performance and } \\
\text { perceived satisfaction with the use of } \\
\text { graphics in an online course. }\end{array}$ \\
\hline 16 & $\begin{array}{l}\text { The audio for the } \\
\text { narration was clear. (If } \\
\text { applicable) }\end{array}$ & $\begin{array}{l}\mathrm{H}_{2}: \text { There is a positive relation between } \\
\text { learners' objective performance and } \\
\text { perceived satisfaction with the use of audio } \\
\text { in the course. }\end{array}$ \\
\hline 17 & $\begin{array}{l}\text { The narration was } \\
\text { appropriately } \\
\text { synchronized with the } \\
\text { text/animation. (If } \\
\text { applicable) }\end{array}$ & $\begin{array}{l}H_{3}: \text { There is a positive relation between } \\
\text { learners' objective performance and } \\
\text { perceived satisfaction with the narration } \\
\text { properly synchronized with the text } \\
\text { animation of the course. }\end{array}$ \\
\hline 15 & $\begin{array}{l}\text { The video format aided } \\
\text { in my understanding of } \\
\text { the subject matter. }\end{array}$ & $\begin{array}{l}H_{4}: \text { There is a positive relation between } \\
\text { learners' objective performance and } \\
\text { perceived satisfaction with video used in the } \\
\text { course. }\end{array}$ \\
\hline 22 & $\begin{array}{l}\text { Why did you enroll for } \\
\text { this course? }\end{array}$ & $\begin{array}{l}\text { H5: After controlling for learners' } \\
\text { perceived satisfaction with the use of } \\
\text { graphics, learners' perceived satisfaction } \\
\text { with the use of audio, learners' perceived } \\
\text { satisfaction with the use of narration } \\
\text { properly synchronized with text animation } \\
\text { and learners' perceived satisfaction with the } \\
\text { use of video, the reason for enrolling in the } \\
\text { course will predict learners' performance. }\end{array}$ \\
\hline
\end{tabular}

\section{Final Score}

In addition to the instrument to measure learner satisfaction with multimedia elements, the e-Learning course contained a final score used as a measure of performance by the learner in knowledge transfer and retention. The e-Learning course contained short knowledge assessments aligned with the learning objectives of the e-Learning course. 
Assessments were a method in which the learning department was able to capture a numerical performance by the learner and evaluate the overall performance. This measure coupled with the learner satisfaction of multimedia elements provided with a measure that could be used by course developers to author e-Learning courses, which in turn provided effectiveness measures.

\section{Procedures}

As previously mentioned, for the purposes of this study, the researcher used secondary data. The learning department within the site location for this study used an instrument developed by a group of instructional designers of which the researcher was a member. The instrument was included in the online course to collect learner satisfaction of online courses. A web-based survey format was used to administer the survey from which the data was used in this study. The instrument was loaded into the LMS, and it was attached to the Medicare course outline. The course outline served as the visual interface for the learner providing a link to visit each course module. The Medicare course was comprised of nine individual modules. Each module contained a scenariobased structure, where cartoon-like characters or avatars presented a life-like scenario that contained audio narration synchronized with on-screen text to present Medicare related topics, and four modules included video files in FLV format. Each video format was under five minutes in duration. To see the general layout of the scenario containing avatars, see Figure 4.

All responses collected from this instrument were stored in the LMS. The LMS uses the SCORM method (Sharable Content Object Reference Model), which means it uses a relational database model. The system maintains separate tables for each set of 
data (e.g., one table for the participation, a separate table for each set of responses from each module), and each record on each of the tables is related to records in the other tables with the same key identification number. Data in the LMS is stored indefinitely, and it is accessible only by members of the learning community of the company. For this study, data utilized was de-identified and contained no personal information.

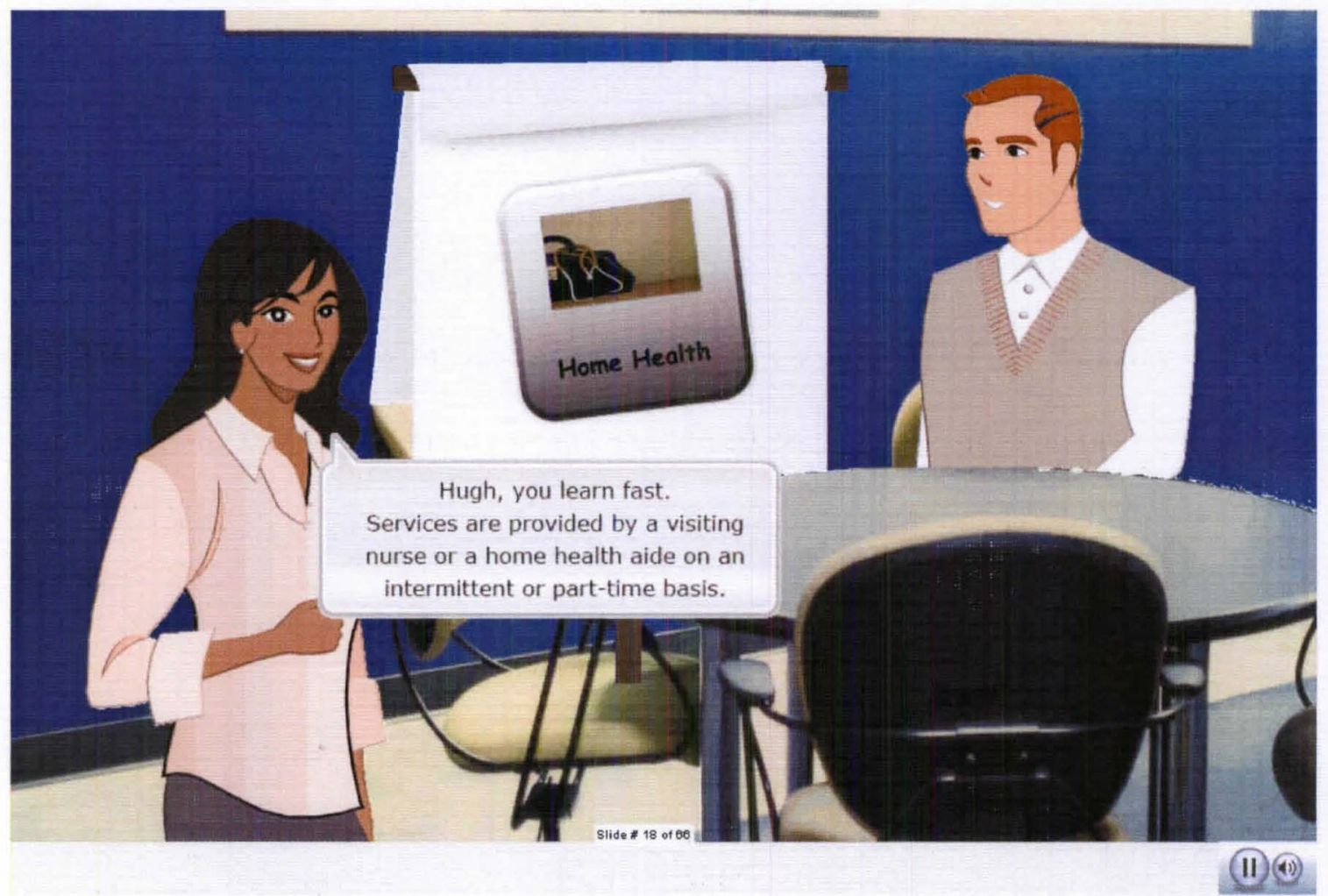

Figure 4. Sample multimedia layout Medicare online course (Medicare 101, 2012).

Prior to any analysis, the researcher obtained permission from the Institutional Review Board to conduct the study. Once the permission was granted, the researcher reached out to the learning department manager for permission to extract data from the relational database. Data was extracted using Microsoft Access, and Structured Query 
Language was used to obtain all data from the survey. The researcher matched final scores and survey responses for each learner.

\section{Data Analysis}

To examine the hypotheses proposed for this study, data was extracted from the LMS. The researcher entered the data in SPSS to calculate the correlation between the employees' course grade and the following variables: (a) self-reported level of satisfaction with the use of graphics in the course; (b) self-reported level of satisfaction with the use of audio in the course; (c) self-reported level of satisfaction with the narration properly synchronized with the text animation of the course; and (d) selfreported level of satisfaction with video used in the course. All quantitative data was examined for statistical relations in SPSS (version 20.0 for Windows). Characteristics analyzed included descriptive statistics such as frequency. An alpha level of .05 (onetailed) was used in all five hypothesis tests. The variables measured in this study were all continuous.

$H_{1}$ : There is a positive relation between learners' objective performance and perceived satisfaction with the use of graphics in an online course.

To test $H_{I}$ the researcher conducted a correlation analysis to determine directionality and strength of relation between: learners' self- reported level of satisfaction with the use of graphics in the course and learners' final grade in the course.

$H_{2}$ : There is a positive relation between learners' objective performance and perceived satisfaction with the use of audio in the course. 
To test $H_{2}$ the researcher conducted a correlation analysis to determine directionality and strength of relation between: learners' self- reported level of satisfaction with the use of audio in the course and learners' final grade in the course.

$H_{3}$ : There is a positive relation between learners' objective performance and perceived satisfaction with the narration properly synchronized with the text animation of the course.

To test $H_{3}$ the researcher conducted a correlation analysis to determine directionality and strength of relation between: learners' self- reported level of satisfaction with the use of narration properly synchronized with the text animation in the course and learners' final grade in the course.

$H_{4}:$ There is a positive relation between learners' objective performance and perceived satisfaction with video used in the course.

To test $H_{4}$ he researcher conducted a correlation analysis to determine directionality and strength of relation between: learners' self- reported level of satisfaction with the use of video in the course and learners' final grade in the course.

$H_{5}$ : After controlling for learners' perceived satisfaction with the use of graphics, learners' perceived satisfaction with the use of audio, learners' perceived satisfaction with the use of narration properly synchronized with text animation and learners' perceived satisfaction with the use of video, the reason for enrolling in the course will predict learners' performance.

To test $H_{5}$, the researcher performed a hierarchical regression analysis, where the combination of satisfaction in the use of graphics, satisfaction in the use of audio, satisfaction in the use of text animation and effectiveness of video and the reason for 
enrolling in the course variables (independent variables) was examined for their unique contributions to course total score (dependent variable).

Hierarchical regression is an advanced form of linear regression, used as an alternative to comparing betas when assessing the importance of independent variables (Aiken \& West, 1991). Such analysis allows a researcher to examine the extent to which regression coefficients vary across different variables, while borrowing strength from the

full sample (Bryk \& Raudenbush, 2002). Because of its ability to detect variance in outcome variables (Bryk \& Raudenbush, 2002), from the pooled variance of independents (e.g., perceived satisfaction in the use of graphics, perceived satisfaction in the use of audio, perceived satisfaction in the use of text animation, perceived satisfaction in the use of video and reason for enrolling) this technique was appropriate for answering this type of research question.

\section{Summary of Method}

Chapter 3 detailed the research processes including the design, sampling and population. This chapter also described the instrument, procedures, data acquisition and its use. Last, this chapter described the analysis performed in this study. 


\section{CHAPTER IV}

\section{RESULTS}

The purpose of this exploratory study was to investigate the impact of multimedia elements in an online course with learner perceived satisfaction and objective performance. This chapter presents results and findings that answer the study's two overarching research questions: (a) is there a relationship between learners' perceived satisfaction of a course and the use of graphics, audio, narration properly synchronized with the text animation and video in the course? and (b) does the reason for enrolling in a course predict the learner score of an online course that contains multimedia? This chapter is organized into three main sections (a) background of the sample, (b) examination of the hypotheses, and (c) a summary of the chapter. To examine the first four hypotheses, four correlation analyses were used to test the effect of multimedia in learner's perceived satisfaction and effectiveness of e-Learning. To examine the fifth hypothesis, a hierarchical regression analysis was used to determine whether multimedia and reason for enrolling in the course could predict learner's final score of e-Learning courses. The instrument used to collect perceived satisfaction measures included three opened ended questions where participants could elaborate on their numerical responses with narrative. Qualitative coding of responses however, was not analyzed as a component of this study. 


\section{Background of the Sample}

The total sample population of respondents $(N=2,401)$, who completed the course and the resulting satisfaction instrument, represented $48 \%$ of the total population registered to take the Medicare 101 online course. Demographic information collected at the time of course completion included participant's current role at the time of enrollment, tenure, and reason for enrolling were examined. No other demographic information was collected for the purpose of the course or this study. Table 7 presents the frequency of all three background variables examined in this study.

\section{Current Role}

A frequency analysis of participant current role indicated that $1 \%(n=13)$ of the respondents reported having the role of Physician, 36\% $(n=855)$ were Nurses, $1 \%(n=$ 21) were Pharmacists, $1 \%(n=29)$ were Pharmacy Technicians, $1 \%(n=28)$ were Social workers, $1 \%(n=23)$ were Licensed Counselors, and $58 \%(n=1395)$ had other nonclinical roles. Approximately one percent $(n=36)$ of respondents did not report their role.

\section{Tenure in Current Role}

A frequency analysis of tenure indicated $41 \%(n=976)$ of the participants have been in the current role between 0 -to- 6 months, $12 \%(n=292)$ reported having been in their current role between six months and one year, 23\% $(n=556)$ reported having been in their current role between one and three years, and 23\% $(n=543)$ reported having been in their current role more than three years. Approximately $1 \%(n=33)$ of participants did not report tenure in their current role. 


\section{Reason for Enrolling}

A frequency analysis of reason for enrolling indicated $17 \%(n=396)$ of learners enrolled in the course because they wanted to learn more about Medicare, $11 \%(n=274)$ enrolled because they were required to take the course, $63 \%(n=1522)$ of learners were signed up by their supervisor to take the course. Approximately $1 \%(n=31)$ of learners did not indicate their reason for enrolling in the course.

Table 7.

Frequency Table of Background Variables.

\begin{tabular}{llrr}
\hline Category & Variable & $f$ & Percent \\
\hline Current Role & Physician & 13 & 1.5 \\
& Nurse & 855 & 35.6 \\
& Pharmacist & 21 & .9 \\
& Pharmacy Technician & 29 & 1.2 \\
& Social Worker & 28 & 1.2 \\
& Licensed Counselor & 23 & 1.0 \\
& Other & 1395 & 58.1 \\
& Total & 2364 & 98.5 \\
& Missing & 37 & 1.5 \\
\hline Tenure & 0-6 months & 976 & 40.6 \\
& 6 months - 1 year & 292 & 12.2 \\
& 1 year - 3 years & 556 & 23.2 \\
& More than 3 years & 543 & 22.6 \\
& Total & 2367 & 98.6 \\
& Missing & 34 & 1.4 \\
\hline Reason for & Wanted to learn more about this & 396 & 16.5 \\
Enrolling & topic & 274 & 11.4 \\
& I was required to take it & 1522 & 63.4 \\
& I was signed up by supervisor & 2192 & 91.3 \\
& Total & 209 & 8.7 \\
\hline & Missing & &
\end{tabular}

\section{Examination of Hypotheses}

Five hypothesized models of learner perceived satisfaction and learner performance were tested using correlational and hierarchical regression analyses. The 
model hypothesized that perceived satisfaction with the use of graphics, perceived satisfaction with the use audio, perceived satisfaction with the use synchronized narration with text animation, and perceived satisfaction with the use of video and reason for enrolling in the online course would be related to the learner objective performance. Prior to testing the model, an underlying assumption about the hierarchical regression analysis technique was examined. The condition examined was multicollinearity (Hinkle et al., 2005). Serious violation of this assumption may make inferences drawn from results of this study untrustworthy especially in the case of large samples sizes such as the case with this study.

\section{Multicollinearity}

Evidence of multicollinearity can exist when variables are highly correlated. When multicollinearity is present within a sample, it is difficult to obtain reliable estimates of individual regression coefficients (Cohen \& Cohen, 1983). For example, when two variables are highly correlated they are basically measuring a similar phenomenon. To avoid multicollinearity, correlations between predictor variables greater than .90 should be removed or combined (Green, 1991). High intercorrelations of predictors increase the standard error of the beta coefficients and make assessment of the unique role of each predictor variable difficult or impossible (Green \& Salkind, 2005). Intercorrelations were checked, and no correlation between predictor variables was found to be greater than .90 . Intercorrelations in this study reached a ceiling of only $r=.64$, thus evidence suggested that multicollinearity was not a primary concern within the results of this sample. 


\section{Correlation Analysis for Testing $\mathrm{H}_{1}$}

$H_{l}$ stated there would be a positive relation between learners' objective performance and perceived satisfaction with the use of graphics in an online course. Zero-order correlational coefficients between the variables of interest were examined for meaningfulness according to effect size standards (Cohen, 1988). Following Cohen's (1988) effect size evaluation criterion, correlational coefficients $<+.28$ are small effects; medium effects range from $+.28-.49 ;$ and, large effects are greater than +.49 .

Perceived satisfaction with the use of graphics in an online course was significantly and positively correlated with learners' objective performance $(r=.039, p<$ $.05)$. This result suggests that learners who reported higher levels of perceived satisfaction with the use of graphics in this online course were also somewhat more likely to complete this online course with a higher objective performance score. The effect size of this association was in the low range (Cohen, 1988). Research evidence supports $H_{l}$. Table 8 provides detailed correlational statistics regarding the relation among learner perceived satisfaction in use of graphics in an online course and learner objective performance. 
Table 8.

Zero-order correlation coefficients for learner objective performance and perceived satisfaction with use of graphics, perceived satisfaction with use of audio, perceived satisfaction with use of narration properly synchronized with text animation, and perceived satisfaction with use of video.

\begin{tabular}{lccccc}
\hline Variables & SC & SGr & SAn & SNa & SVd \\
\hline SC & -- & & & & \\
SGr & $.039^{*}$ & -- & & & \\
SAn & $.052^{* *}$ & $.497^{* *}$ & -- & & \\
SNa & $.060^{* *}$ & $.467^{* *}$ & $.645^{* *}$ & -- & \\
$\mathrm{SVd}$ & $.059^{* *}$ & $.522^{* *}$ & $.447^{* *}$ & $.487^{* *}$ & -- \\
\hline
\end{tabular}

Note. ${ }^{*} p<.05$. SGr is use of graphic. ${ }^{* *} p<.01$. SAn is use of Audio. $\mathrm{SNa}$ is the use of synchronized narration with animation, SVd is use of video. $N=2401$.

\section{Correlation Analysis for Testing $\mathbf{H}_{2}$}

$H_{2}$ stated that there would be a positive relation between learners' objective performance and perceived satisfaction with the use of audio in an online course. Zeroorder correlational coefficients between the variables of interest were examined for meaningfulness according to effect size standards (Cohen, 1988). Perceived satisfaction with the use of audio in an online course was significantly and positively correlated with learners' objective performance $(r=.052, p<.01)$. This result suggested that learners who reported higher levels of perceived satisfaction with the use of audio in this online course were also more likely to complete the online course with a higher objective 
performance score. The effect size of this association was in the low range (Cohen, 1988). Research evidence supports $H_{2}$. See Table 8 for detailed correlational statistics regarding the relation among learner perceived satisfaction in use of audio in an online course and learner objective performance.

\section{Correlation Analysis for Testing $\mathrm{H}_{3}$}

$H_{3}$ stated that there would be a positive relation between learners' objective performance and perceived satisfaction with narration properly synchronized with text animation in an online course. Zero-order correlational coefficients between the variables of interest were examined for meaningfulness according to effect size standards (Cohen, 1988). Perceived satisfaction with narration properly synchronized with text animation in an online course was significantly and positively correlated with learners' objective performance $(r=.060, p<.01)$. Results suggested that learners who reported higher levels of perceived satisfaction with narration properly synchronized with text animation in this online course were also more likely to complete the online course with a higher objective performance score. The effect size of this association was in the low range (Cohen, 1988). Research evidence supports $H_{3}$. See Table 8 for detailed correlational statistics regarding the relation among learner perceived satisfaction in use of narration properly synchronized with text animation in an online course and learner objective performance.

\section{Correlation Analysis for Testing $\mathrm{H}_{4}$}

$\mathrm{H}_{4}$ stated that there would be a positive relation between learners' objective performance and perceived satisfaction with the use of video in an online course. Zeroorder correlational coefficients between the variables of interest were examined for 
meaningfulness according to effect size standards (Cohen, 1988). Perceived satisfaction with the use of video in an online course was significantly and positively correlated with learners' objective performance $(r=.059, p<.01)$. This result suggests that learners who reported higher levels of perceived satisfaction with the use of video in this online course were also more likely to complete the online course with a higher objective performance score. The effect size of this association was in the low range (Cohen, 1988). Research evidence supports $H_{4}$. See Table 8 for detailed correlational statistics regarding the relation among learner perceived satisfaction in use of video in an online course and learner objective performance.

\section{Hierarchical Regression Analysis for Testing $\mathrm{H}_{5}$}

A hierarchical regression analysis was performed to test $H_{5}$ which stated that after controlling for learners' perceived satisfaction with the use of graphics, learner's perceived satisfaction with the use of audio, learners' perceived satisfaction with the use of narration properly synchronized with text animation, and learners' perceived satisfaction with the use of video, reason for enrolling in the course would predict learners' performance. The dependent variable examined was objective performance score. Perceived satisfaction with graphics, perceived satisfaction with audio, perceived satisfaction with narration and perceived satisfaction with video were entered as the first variables in the model (first block). Reason for enrolling in the course was loaded into the second model (second block). Detailed results of the hierarchical regression analysis on objective performance score can be found in Table 9. 
Table 9.

Summary hierarchical regression analysis with learner perceived satisfaction with graphics, learner perceived satisfaction with audio, learner perceived satisfaction with narration properly synchronized with text animation, and learner perceived satisfaction with video, and reason for enrollment predicting performance.

\begin{tabular}{|c|c|c|c|c|}
\hline \multirow[b]{2}{*}{ Variable } & \multicolumn{4}{|c|}{ Objective Performance Score } \\
\hline & $\beta$ & $R$ & $\Delta R^{2}$ & $\begin{array}{c}\text { Sig. } F \\
\text { Change }\end{array}$ \\
\hline \multicolumn{5}{|l|}{ Step 1} \\
\hline \multicolumn{5}{|l|}{ Perceived Satisfaction with Multimedia } \\
\hline Perceived Satisfaction with & -.00 & & & \\
\hline \multicolumn{5}{|l|}{ graphics } \\
\hline Perceived Satisfaction with audio & .02 & & & \\
\hline Perceived Satisfaction with & .03 & & & \\
\hline \multicolumn{5}{|l|}{ narration } \\
\hline Perceived Satisfaction with video & .04 & & & \\
\hline Block & & .07 & .003 & .02 \\
\hline \multicolumn{5}{|l|}{ Step 2} \\
\hline Reason for Enrollment & -.00 & & & \\
\hline Block & & .07 & .003 & .92 \\
\hline Total adjusted $R^{2}$ & & & .003 & \\
\hline
\end{tabular}

Note. ${ }^{*} p<.05$ level 
Testing the first regression model, in the first block, the four scales of perceived satisfaction with graphics $(\beta=-.00)$, audio $(\beta=.02, p<.05)$, narration $(\beta=.03, p<.05)$, and video $(\beta=.04, p<.05)$ contributed unique variance to the prediction of learner objective performance $\left(R^{2}=.003, p<.05\right)$ in the regression equation. In the second block, after controlling for perceived satisfaction with multimedia, reason for enrollment in the online course did not contribute additional variance to the regression equation $\left(R^{2}=\right.$ $-.00) . H_{5}$ was not supported in this model. Accordingly, learners who reported higher perceived satisfaction with graphics, higher perceived satisfaction with audio, higher perceived satisfaction with narration and higher perceived satisfaction with video were more likely to have higher objective performance scores in the online course than reason for enrolling the course. These findings suggest that the inclusion of multimedia elements such as graphics, audio, narration and video in an online course contribute, albeit slightly according to these findings, to learner's higher objective performance scores. Reason for enrolling in the online course did not contribute and predictive variance to learners' objective performance in the course score. Overall, the regression model explained $0.3 \%$ of the variance in objective performance (small effect size; Cohen, 1988).

As an additional step to ensure that issues of multicollinearity did not skew results within this sample, the variance inflation factor (VIF) was examined. VIF statistically quantifies the degree of multicollinearity between variables by providing an index that estimates how much variance is inflated due to collinearity (Green, 1991). VIF scores that approach 10.0 provide evidence of potential multicollinearity. None of the variables examined in this hierarchical regression analysis met or exceeded 10.0 (all less than 1.9). 


\section{Summary}

Results of this study partially supported the hypotheses proposed in this study. The variables included in $H_{l}$ through $H_{4}$, perceived satisfaction with use of graphics, perceived satisfaction with use of audio, perceived satisfaction with use of narration and perceived satisfaction with use of video were significantly associated with learner objective performance scores. Therefore, hypotheses $H_{1}$ through $H_{4}$ were supported by the findings of this study. After controlling for learner perceived satisfaction with use of graphics, perceived satisfaction with use of audio, perceived satisfaction with use of narration and perceived satisfaction with use of video, reasons for enrolling in an online course did not predict learners' objective performance in the online course.

Consequently, $H_{5}$ was rejected. Chapter 5 discusses the results and implications of these findings for research, theory, and practice. 


\section{CHAPTER V}

\section{DISCUSSION}

The purpose of this exploratory study was to investigate the impact of multimedia elements in an online course with learner perceived satisfaction and objective performance. This chapter provides a summary of the study; a discussion of the results and a narrative of the implications for theory, research, and practice, followed by limitations of this study.

\section{Summary of the Study}

The availability of the Internet and its ever-increasing bandwidth lines allow greater use of multimedia (Herder et al., 2002). More Internet availability and its increasing bandwidth lines have captured more users, such that as of November 2000 the number of people online worldwide equaled 407.1 million (Driscoll, 2000). Course developers have the potential to take advantage of the Internet availability and its increasing bandwidth to design e-Learning experiences with more multimedia elements (Bolliger et al., 2010). The use of e-Learning with multimedia elements such as graphics, audio, narration, and video are considered a tactical solution to strengthen Just-In-Time training to leverage employee performance in organizations (Driscoll, 2002).

Scholars, educational institutions, and practitioners have started to consider issues of satisfaction and effectiveness when suggesting development and delivery techniques for e-Learning content. Researchers considered satisfaction and behavioral intention of 
learners using multimedia resources (Diezmann \& Watters, 2002). Learners have demonstrated higher-order learning outcomes when accessing modules with multimedia elements such as audio, narration with animation and video (Kekkonen-Moneta \& Moneta, 2002). Despite this linkage, little research however has analyzed the relationship of multimedia components in e-Learning and learner satisfaction and learner effectiveness.

The purpose of this study was to determine how the use of multimedia components, such as animation, audio and video, in online courses is related to perceived learner satisfaction and learning effectiveness. Two overarching research questions guided this proposed study: (a) is there a relationship between learners' perceived satisfaction of a course and the use of graphics, audio, narration properly synchronized with the text animation and video in the course? and (b) does the reason for enrolling in a course predict the learner score of an online course that contains multimedia? To explore these research questions, five hypotheses were proposed for examination:

$H_{I}$ : There is a positive relation between learners' objective performance and perceived satisfaction with the use of graphics in an online course.

$H_{2}$ : There is a positive relation between learners' objective performance and satisfaction with the use of audio in the course.

$H_{3}$ : There is a positive relation between learners' objective performance and perceived satisfaction with the narration properly synchronized with the text animation of the course. 
$H_{4}$ : There is a positive relation between learners' objective performance and perceived satisfaction with video used in the course.

$H_{5}$ : After controlling for learners' perceived satisfaction with the use of graphics, learners' perceived satisfaction with the use of audio, learners' perceived satisfaction with the use of narration properly synchronized with text animation and learners' perceived satisfaction with the use of video, the reason for enrolling in the course will predict learners' performance.

The researcher used retrospective data to investigate the relationships among the variables of interest. Data were originally collected for a full calendar year by a learning department of a multinational publicly-traded healthcare company. The learner satisfaction survey and performance score instruments were attached to an online course on Medicare basic education. Results of both satisfaction and performance instruments were housed in the company's LMS. The online course was initially intended for employees with Medicare related responsibilities in the organization. Employees from other areas across the organization were self-identified as additional target audience. The total sample for the retrospective data resulted in a total of 2,401 respondents, representing $48 \%$ of the total population registered for the online course.

\section{Discussion of Results}

The following section discusses the results of each hypothesis tested. Results of this study suggested there were statistically significant relations to explore among the variables of interest. All five hypotheses are explored followed by a summary of this section. 


\section{Hypothesis 1}

The first hypothesis stated that there would be a positive relation between learners' objective performance and learners' perceived satisfaction with the use of graphics in an online course. Results from the correlational analysis indicated there was a significant positive relation between learners' objective performance and learners' perceived satisfaction with the use of graphics in an online course. The effect size of this correlation was positively significant, although with a low effect size. This finding supports the use of and inclusion of graphics in online course content as a way to enhance students' satisfaction and to potentially affect student objective performance. Although the effect size reflected significance, it is important to highlight that the results supported the relationship of graphics with learners' perceived satisfaction and effectiveness.

Furthermore, the significance is relevant when graphics are combined with the other elements of multimedia (i.e. audio, narration and video). These findings support the Multimedia Learning Theory formulated by Clark and Mayer (2008). This theory lists three cognitive demands a learner encounters essential processing, incidental processing, and representational holding, and the significance of the results of this study support the function of graphics in the learner representational holding demand. Learners can use the visuals from graphics to retain information in working memory over a period of time. These results also support significant statistical findings $(p<.05)$ that showed higher knowledge retention by learners (Schwamborn et al., 2011). Contrary to creating online courses with only text as multimedia, the use of graphics in this study demonstrated the ability to share a positive relation with learner's satisfaction and objective performance. 


\section{Hypothesis 2}

The second hypothesis stated that there would be a positive relation between learners' objective performance and learners' perceived satisfaction with the use of audio in online courses. Results from the correlation analysis indicated there was a significant positive relation between learners' objective performance and learners' perceived satisfaction with the use of audio in an online course. Results of the correlation were significantly positive, and support the use of audio in online courses. In addition to including text, and graphics in an online course, the inclusion of audio tends to have an effect on learners' objective performance and perceived satisfaction to the point that they provide a significant reason for course developers to include audio in online courses.

Results of this study are concordant with other research that found multimedia to support knowledge generations for high-ability learners (Plass et al., 2003). Researchers found a significant interaction of verbal and visual abilities. These study findings enhance the significance of the value of verbal interactions with the relation of the use of audio in online courses and learners' perceived satisfaction. These results reinforce findings by Jones and Plass (2002) that demonstrated learners with audio as multimedia elements performed higher $(p<.05)$. This study also found the significant effect of audio in learners' perceived satisfaction to be related. Rather than demonstrating audio as being a causality of learners' perceived satisfaction, it is important to note the relevance of the audio element in conjunction with narration properly synchronized with animated text and video to have a relation with learners' perceived satisfaction and effectiveness. These results augment findings by Austin (2009) where audio produced higher scores in learners' performance compared to scores by learners presented with only text. Austin 
further suggested multimedia elements contribute to the modality and redundancy effects, and these effects in turn had a positive impact in learners test scores.

\section{Hypothesis 3}

The third hypothesis stated that there would be a positive relation between learners' objective performance and learners' perceived satisfaction with the use of narration properly synchronized with text animation in online courses. Results from the correlation analysis indicated there was a significant positive relation between learners' objective performance and learners' perceived satisfaction with the use of narration properly synchronized with text animation in an online course. The effect size of this correlation was positively significant, and the finding suggests that it is favorable to consider the inclusion of narration properly synchronized with text animation in online courses. This result provides further evidence to the meaningful learning impact of multimedia indicated by the generative and dual coding theories (Diezmann $\&$ Watters, 2002). Learners can select words and images from the material presented; such material contains narration synchronized with text animation without causing a cognitive overload. The use of visual and auditory channels enhances the experience and capacity of a learner selecting, organizing and integrating information to further generate new knowledge.

This study presents more evidence to support the use of narration in online courses as found in Austin's research (2009). Austin found learners' scores to be positively affected by the use of animation and narration more than animation and text alone $(p<.001)$ concluding that using multimedia elements in online courses was beneficial to register learners' effectiveness (Austin, 2009). 


\section{Hypothesis 4}

The fourth hypothesis stated that there would be a positive relation between learners' objective performance and learners' perceived satisfaction with the use of video in online courses. Results from the correlation analysis indicated there was a significant positive relation between learners' objective performance and learners' perceived satisfaction with the use of video in an online course. The effect size of this correlation was positively significant, and supports that it is favorable to consider the use of video in online courses. While these results do not account for causality, their significant relation provides further evidence for the use of video in online courses to account for a different way to present content. Moreover, by providing evidence for the relation between learners' objective performance and learners' perceived satisfaction, this study supports Guan's (2009) findings about significant differences in performance of learners presented with video content.

In combination with the multiple variables of this study (i.e., perceived satisfaction with the use of graphics, perceived satisfaction with the use of audio, and perceived satisfaction with the use of narration properly synchronized with animated text), learners who take online courses with the multimedia elements mentioned demonstrated a positive significant relation between their objective performance and their perceived satisfaction with the use of multimedia in an online course. 


\section{Hypothesis 5}

The fifth hypothesis stated that after controlling for learners' satisfaction with the use of graphics, learners' satisfaction with the use of audio, learners' satisfaction with the use of text animation and learner satisfaction with the use of video, the reason for enrolling in the course would predict learners' objective performance. Results from the hierarchical regression analysis presented evidence that the reason for enrolling in the course did not predict learners' objective performance. Thus, results did not show support for $H_{5}$. This finding provides an objective perspective in relation to the reason why learners in a company would enroll in an online course.

Learning departments sometimes create and post online courses for specific audiences. However, the topic presented may be of interest to other audiences in the organization and these audiences may feel as if they want to learn more about a specific topic. Two more reasons are taken into account: learners of a department are required to enroll into the online course as part of their role, or learners' supervisors felt the online course would be a good developmental opportunity, whether to expand their existing role or become more effective in the current role. Despite the previous mentioned reasons, this hypothesis aimed at exploring the ability to predict objective performance of online courses. Results did not find strength in the reasons mentioned. Therefore, it is evident that learners' objective performance is not affected when they are being required to take an online course, their supervisor signed them up or if it was an individual decision to enroll in an online course.

Notwithstanding, learners' perceived satisfaction with audio, learners' perceived satisfaction with narration properly synchronized with text animation, and learners' 
perceived satisfaction with video, were influential for learners' objective performance (see Figure 5). Learners' perceived satisfaction with graphics was not influential in learners' objective performance. Learners see graphics in virtually any material they have available. Thus, results from this study support that the concurrent use of audio, narration properly synchronized, and video are relevant elements of multimedia to consider for future development of online courses. Further research is needed to confirm the strength of the predictive relation between learners' perceived satisfaction with audio, learners' perceived satisfaction with narration properly synchronized with text animation and learners' perceived satisfaction with video and learners' objective performance.

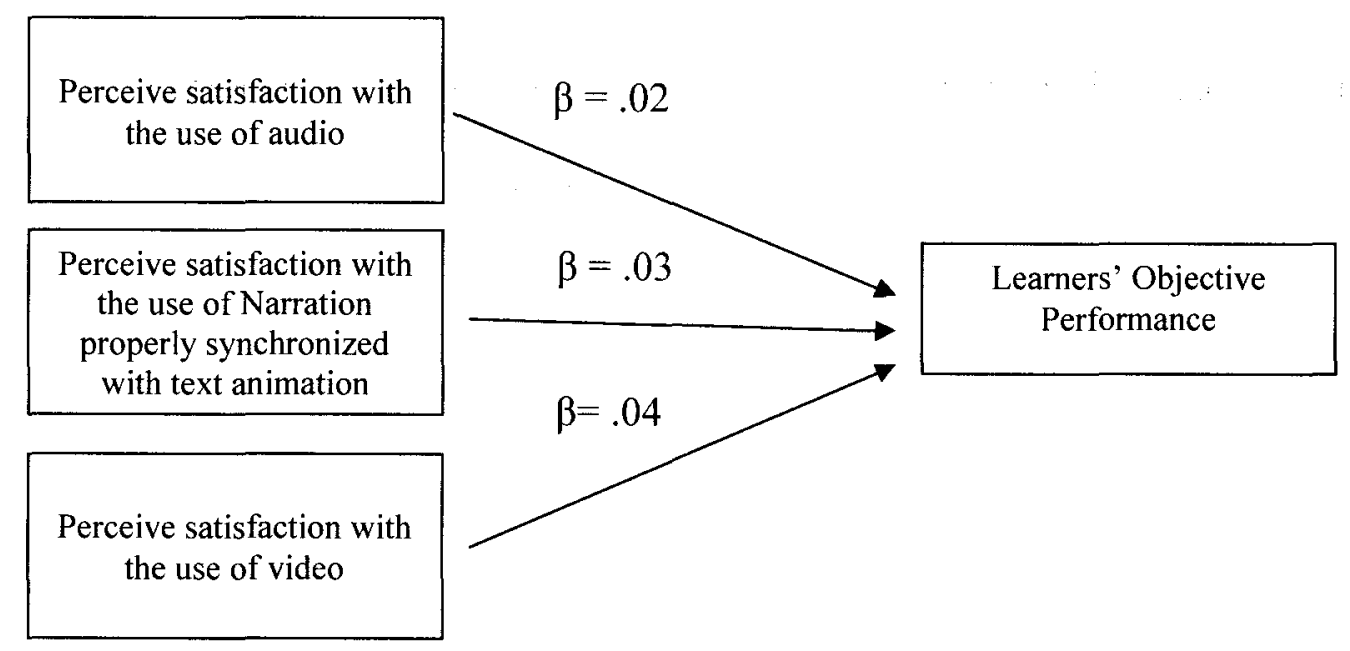

Figure 5. Predictors of Objective Performance.

\section{Implications for Theory, Research and Practice}

There was evidence that the use of graphics, audio, narration properly synchronized with text animation, and video has a significant positive effect on learners' perceived satisfaction and objective performance. With the emphasis of Just-in-Time 
learning in the work place by means of e-Learning and its appeal to cognitive theory of multimedia (Driscoll, 2002; Moreno \& Mayer, 2000), scholars, researchers and practitioners continue to take a closer look at the use of multimedia elements and their effectiveness and satisfaction in learners. The following sections examine implications of this study to multimedia theory building, research and practice.

\section{Implications for Theory}

This study supports and extends Moreno and Mayer's (2000) cognitive theory of multimedia and Mayer's (1997) generative theory of multimedia learning by providing empirical evidence of the positive relation of learner satisfaction with the use of multimedia elements and objective performance. For example, cognitive and generative theories rest in the foundation of learners' dual channels to absorb information. Results from this study provided evidence of further linkages to objective performance. Moreover online courses with multimedia components provide learners with an aid to support the three cognitive demands: (a) essential processing, (b) incidental processing, and (c) representational holding. Learners can absorb content through both channels, creating a cognitive load balance when they have graphics, audio, narration, and video, in addition to the common text in many online courses. This study's results suggested that the more significant impact of multimedia elements in an online course include audio, narration properly synchronized with text animation and video and not reason for enrollment in a course. When considering the three elements of multimedia, the integration of information and generation of knowledge by learners is incidental as presented in Mayer's (1997) Generative Theory of Multimedia Learning. Thus, this study suggested that the use of the three elements of multimedia (i.e., audio, narration properly 
synchronized with text animation, and video in some combination) provided more effective information integration and knowledge generation.

This study results supported the dual code theory, and theory of multimedia learning presented by Paivio (1986) and Mayer (1997) respectively. Both theories highlight the importance of the aural and visual channels of input in learners. These results supported the benefit of using both channels with audio, narration and video in an online course by finding a relation with learners' perceived satisfaction. A dwelling point on the results of this study was to note the low effect size of the relation between the learner perceived satisfaction with the elements of multimedia and the objective performance. McNeil et al., (2009) found positive effects of multimedia in online courses, although low effects as well. It was interesting to find low effects of relationship considering the large sample size.

In addition, results of this study suggested that further exploration of implications of more multimedia elements and the impact they have in learners' process of integration is relevant. Theory describes the benefit of using multiple modalities to present information to appeal to learners' two input channels (e.g., auditory and visual). Theory could further explore the value and relevance of each element. Using audio in online courses appeals to the learners' auditory channel. Theory suggests the auditory channel provides one way to input information, yet it does not provide guiding principles as to the amount of information that should be included in this format, and the effect it has on the learners' satisfaction dimension. 


\section{Implications for Research}

Results of this study supported research that indicates learners' perceived videobased instruction to be more memorable than text-based instruction (Choi \& Johnson, 2005). Learners that find instruction more memorable tend to have higher levels of performance. This study results reinforce the statement that perceived satisfaction when using video in e-Learning has a relation with objective performance. Researchers are encouraged to further test the effects of multimedia in learners' perceived satisfaction and objective performance in the work place. Future findings will give more strength to the reasons for including multimedia in online courses in the workplace. This is extremely important for organizations as they continue to explore ways to sustain the learning and development with low budget impact (Driscoll, 2002). Also, as organizations continue to explore and gain more traction in the focus on employee engagement, when learning in the workplace becomes a factor that is believed to contribute with employee engagement (Shuck \& Wollard, 2008). Future research may explore the causalities of learner perceived satisfaction and objective performance with multimedia elements in online courses. It is important to note the results of this study are representative of learners in the workplace. However, as a direct extension, researchers might consider other variables such as reason for enrollment and topic relevance of the course that need further exploration. The topic of the online course used in this study is non-specific in the area of health insurance; consideration of more specific topics for employees is also an important factor to explore. It will be relevant to consider the relation of perceived satisfaction and objective performance of online courses by learners in other industries with other topics specific to those industries, primarily to measure the relation when topics other than the 
topic used in the online course used in this study. The use of audio and video particularly, provides more latitude for course developers to use e-Learning for topics that relate to hard skills. The opportunity to explore the effects of multimedia elements for topics related to soft skills, where human contact is simulated by adding one way audio and video, albeit the interpersonal interaction is generally not present in online courses.

Research has found that learning has a positive effect on learners' engagement in online courses by incorporating interpersonal interaction in online courses at the workplace (Githens, 2006). It would be beneficial to find the significance of combining multimedia elements (i.e. graphics, audio, narration, and video) with interpersonal interactions in online courses and their effect on perceived satisfaction and objective performance. In addition, the topic of learner satisfaction in the workplace has significance in the emerging area of employee engagement. Training through learning in the workplace is traditionally believed to contribute to heightened levels of employee engagement (Shuck \& Wollard, 2008). It is relevant to consider the impact of e-Learning in the workplace, when learning is considered a new approach to the traditional aspect of employee engagement (Shuck \& Wollard, 2008). Moreover, e-Learning could increase learners' perceived satisfaction, and consequentially have a reinforcing effect on employee engagement; this remains underexplored in the literature. Despite results found in this study, there is value in further exploring the effects of multimedia elements in learners' perceived satisfaction and effectiveness.

Further, the use of retrospective data in a non-experimental study is valuable. Nevertheless an experimental study could reinforce current findings. It could also explore in more detail the effects of learners' perceived satisfaction with the use of graphics. An 
experimental study would provide a good way to compare results of perceived satisfaction and objective performance of learners from a controlled group. To setup an experimental study, the researcher would use two versions of the same online course. The first version of the online course would include elements of multimedia, whereas the second version, presenting the same content, would not include any multimedia. The course design could account for the same sequence and segment duration of each part of the online course. The only difference would be the presence or removal of multimedia elements. The controlled group would then be presented with the version of the online course that contained elements of multimedia. Both online courses should include the same satisfaction measurement instrument and same objective performance assessments. The use of psychometric analysis such as an analysis of variance (ANOVA) would provide statistical values to further test the effects of multimedia elements of learner's perceived satisfaction and objective performance in online courses.

This study considered the primary elements of multimedia: (a) graphics, (b) audio, (c) narration properly synchronized with text animation, and (d) video. The continuous evolution of Internet technology and network bandwidths, complex multimedia such as 3D (three dimensional), and virtual reality environments may have more reason to be prominent in the training and development arena. Currently, some kinesthetic tasks are difficult to train online. All kinesthetic tasks are confined as being a video demonstration in a 2D environment, and others to aural description.

Another consideration to further study will be to measure the effects of multimedia elements with learner perceived satisfaction with soft skills. Course developers oftentimes encounter the challenge to convey ideas and concepts related to 
non-technical skills. It is more common to find videos or narration that describes the use of a computer system used at work, rather than a video or any narration pertaining to soft skills such as negotiation skills, for example. In addition to the topics conveyed using multimedia elements in online courses, the amount of multimedia elements used in an online course is something to explore further. Considering the cost incurred by training departments in the creation of online courses with multimedia elements (Table 2) it will be beneficial for course developers to have a better understanding of the amount of multimedia elements used in an online course and the effect of a given amount of multimedia elements. Last, the duration of a single instance of a multimedia element may be worth exploring further. Results of this study indicated the use of audio, narration and video combined have a significant statistical effect on learners' satisfaction and objective performance. The other factor to consider will be the duration of time for each of these elements and their effect on learners' satisfaction and objective performance.

\section{Implications for Practice}

Course developers frequently use theories and principles explored and presented by researchers, which provide methods to develop or enhance online learning. Theories such as Cognitive Theory of Multimedia Learning (Mayer, 1997) and principles like Justin-Time learning (Driscoll, 2002) are considerably taken into account by practitioners to create online courses. One of the challenges for course developers is that they have few sources with quantitative data to support developers' effort to include multimedia in online courses. The biggest challenge practitioners experience is the reluctance by some about adding multimedia elements in online courses. Those who have an academic background may know of techniques suggested by Margaret Driscoll or Ruth Colvin 
Clark. These authors present a number of techniques and concepts to apply when developing online courses, and support the use of multimedia elements such as Graphics for Learning (Clark, 2004) or Web-Based Training (Driscoll, 2002). On the other hand, those who have developed their skill in a non-academic environment do not have enough literature ground to assert the effectiveness of multimedia elements' use in online courses.

Furthermore, much of the research used and consulted by both types of practitioners does not have readily available metrics that demonstrate the benefit of using multimedia elements in online courses. Two areas of attention around using multimedia elements are learners' perceived satisfaction and objective performance with e-Learning that contains multimedia elements. Research has found that learners' satisfaction is positively affected by online self-efficacy (Gunawardena et al., 2010). However, the effect of multimedia elements use in online courses and the effect of multimedia elements in combination with online self-efficacy do not seem evident to practitioners. Training departments consider the cost of multimedia design when recommending an online learning solution, as the cost may not offset the benefit or the number of targeted learners. The findings of this study can help course developers and training departments make a case for the return-on-investment of more time and budget dedicated to inclusion of multimedia elements in online courses due to the positive results multimedia elements have in learners' satisfaction and objective performance, which in turn also provide evidence about the benefits of using multimedia elements in online courses.

Results of this study indicated that including multimedia elements in online courses has a positive effect in learners' perceived satisfaction. Moreover, the results 
from this study strengthen research by Schwamborn et al., (2011) in which they found that multimedia helps learners generate information more effectively $(p<.05)$. These results also suggest the combined use of audio, narration, and video has a significant effect on learners' performance. Results strengthen Plass et al. (2003) findings that indicate more knowledge generation for high-ability learners. Researchers considered spatial, verbal, and visual abilities in learners, which are concurrent with findings of this study that indicate the positive relation and effect in learners' perceived satisfaction and objective performance when audio, narration and video are present in online courses. This could mean course developers should consider leveraging all three elements of multimedia rather than one single element. Findings by Romanov \& Nevgi (2007) indicate that students, who watch video clips as part of online courses, achieve higher course grades. Therefore, course developers should continue considering the use of multimedia elements more often than not when developing online courses. Course developers might also consider the use of a combination of the three elements of multimedia (i.e. audio, narration and video), instead of focusing on only a single element at a time. Finally, the use of objective performance data adds substantial strength to the results of this study.

\section{Limitations of the Study}

While this study explored the effects of multimedia elements in students' perceived satisfaction and effectiveness, no study is without limitations. For example, this study did not account for the varied learning styles of learners, which research might suggest can influence learner based outcomes such as a score on an objective test. Conway and Christiansen (2005) found the auditory channel to afford better learning, 
among the modality effects they researched. The modality effect in learners is something for which this study did not control and it would be considered the auditory learning style. The second limitation of this study is the use of retrospective data of a course offering within a large, multinational corporation and not a random sampling of participants within the wider population. For the purposes of this study, it was not possible to perform an experiment to obtain comparative results of the effects of multimedia elements due to the proprietary nature of the course design and its use with a private corporation; however, as previously mentioned, the use of objective based performance data rather than self-report measures had to be weighed in relation to this limitation.

Third, the instrument used in this course was developed prior to this study and was comprised of single items designed to measure perceived satisfaction with efficiency instead of a validated scale previously garnered from the literature. The rationale behind the instrument design was that in a fast paced, corporate- environment, it was incredibly challenging to construct an instrument using a scale approach that contained more than 25 questions. In the workplace, surveys with a large number of questions tend to be bypassed by employees in the interest of time especially as a non-required component of the course. Thus, the significance of these findings is weighted more toward practical implications given the objective performance scores utilized to analyze the hypotheses. This provides the study with strong practical significance for the workplace although its noted statistical limitations must be considered in context. Caution should be used when generalizing beyond the results of this study. As mentioned earlier, future research should 
consider using a more robust scale approach, employing validated, well-researched methods to further explore these findings.

Finally, the data, findings and course used in this study apply only to healthcare; specifically to the one healthcare company, which served as the unique context for this study. The specific industry limits the ability to generalize results other industries that may have other factors to consider when evaluating objective performance or the use of multimedia in course design. For example, this study used course scores to operationalize the objective performance, whereas other industries may need to operationalize objective performance with other measures such as observation scales or assembled units.

Nonetheless, it is important to note the results of this study are interestingly practical and utilitarian, which is seldom a benefit within this area of research. 


\section{REFERENCES}

Adobe (2010). Adobe flash video file format specification version 10.1. Retrieved from: http://www.adobe.com

Aiken, L. S., \& West, S. G. (1991). Multiple regression: Testing and interpreting Interactions. Newbury Park, CA: Sage.

Austin, K. (2009). Multimedia learning: Cognitive individual differences and display design techniques predict transfer learning with multimedia learning modules. Computers \& Education, 53, 1339-1354.

Barthold, J. (2001). AccelerNet prepares for two-way UHF high-speed data service. Telephony, 240(12), 104-107.

Bolliger, D. (2010). Impact of podcasting on student motivation in the online learning environment. Computers \& Education, 55, 714-722.

Boslaugh, S. (2007). Secondary Data Sources for Public Health: A Practical Guide. Cambridge University Press. Retrieved from

http://sfcs.cals.arizona.edu/azsearch/sites/sfcs.cals.arizona.edu.azsearch/files/Boslaugh, \% 202007.pdf

Brown, S., Kirkpatrick, M., \& Wrisley, C. (2003). Evaluative parameters of a web-based nursing leadership course from the learnersl' perspective. Journal of Nursing Education, 42(3), 134-137.

Bryk, A.S., \& Raudenbush, S.W. (2002). Hierarchical linear models: Applications and data analysis methods. Newbury Park, CA: Sage.

Carlton, K., \& Ryan, M. (1998). Designing courses for the internet: a conceptual approach. Nurse Educator , 23(3), 45-50.

Cekada, T. (2011). Need Training? Conducting an effective needs assessment. Professional Safety, 56(12), 28-34.

Choi, H., \& Johnson, S. (2005). The effect of context-based video instruction on learning and motivation in online courses. The American Journal of Distance Education, 19(4), 215-227. 
Clark, R., \& Mayer, R. (2008). E-learning and the science of instruction. $\left(2^{\text {nd }}\right.$ ed). San Francisco: Jossey-Bass/Pfeiffer.

Cohen, J., \& Cohen, P. (1983). Applied multiple regression/correlation analysis for the behavioral sciences. Hillsdale, NJ: Erlbaum.

Cohen, J. (1988). Statistical power analysis for the behavioral sciences. San Diego, CA: Academic Press.

Davis, H. (2008). Copyright in the online course environment. Journal of Library Administration, 45. 513-515.

Driscoll, M. (2002). Web-based training: creating e-learning experiences. $\left(2^{\text {nd }}\right.$ ed). San Francisco: Jossey-Bass/Pfeiffer.

Diezmann, C.M. \& Watters, J.J. (2002). A theoretical framework for multimedia resources: A case from science education. Proceedings Australian Association for Research in Education Conference, Brisbane.

Dillman, D. A. (2000). Mail and internet surveys: The tailored design method (2nd ed.). New York: John Wiley \& Sons.

Farthing, J. (2912). What is the file extension mpg4. eHow. Retrieved from http://www.ehow.com/facts_5598429_file-extension_-mpg4_html

Fuglseth, A. M. \& Gronhaug, K. (2003). A toolkit for measurement of organizational learning: Methodological requirements and an illustrative example. Journal of Universal Computer Science, 9(12), 1487-1499.

Gilbert, T. (1976). Training: The $\$ 100$ billion opportunity. Training and Development Journal, 30(11), 3-6.

Githens, R. (2006). Cautions: implementing interpersonal interaction in workplace elearning. TechTrends, 50(5), 21-27.

Green, S.B. (1991). How many subjects does it take to do a regression analysis? Multivariate Behavioral Research, 26, 449-510.

Green, S. B., \& Salkind, N. J. (2005). Using SPSS for Windows and Macintosh (6 $6^{\text {th }}$ ed.). Upper Saddle River, NJ: Pearson.

Guan, Y. (2009). A study on the learning efficiency of multimedia-presented, computerbased science information. Educational Technology \& Society, 12(1), 62-72. 
Gunawardena, C.N., Linder-VanBerschot, J.A., LaPointe, D.K. \& Rao, L. (2010). Predictors of learner satisfaction and transfer or learning in a corporate online education program. American Journal of Distance Education, 24, 207-226.

Herder, P.M., Subrahmanian, E., Talukdar, S., Turk, A., \& Westerberg, A. (2002). The use of video-taped lectures and web-based communication in teaching: A distance-teaching and cross-Atlantic collaboration experiment. European Journal of Engineering Education, 27(1), 39-48.

Herzog, R., Kinuwaki, S., Myszkowski, K \& Seidel, H. (2008). Render2mpeg: A perception-based framework towards integrating rendering and video compression. Eurographics,27(2), 183-192.

Hinkle, D. E., Wiersma, W., \& Jurs, S. G. (2003). Applied statistics for the behavioral sciences (5th ed). New York: Houghton Mifflin.

Huff-Eibl, R., Voyles, J.F., \& Brewer, M. (2011). Competency-based hiring, job description, and performance goals: The value of an integrated system. Journal of Library Administration, 51(7-8), 673-691.

Hussein, E., M.O.M., \& Cronje, J.C. (2010). Defining mobile learning in the higher education landscape. Educational Technology \& Society, 13(3)m 12-21.

Hwang, G., Sung, H., Hung, C., Huang, I., \& Tsai, C. (2012). Development of a personalized educational computer game based on students' learning styles. Educational Tech Research Dev, 60, 623-638.

Jereb, E. \& Smitek, B. (2006). Applying multimedia instruction in e-learning.innovations in Education and Teaching International, 43(1), 15-27.

Jones, L.C. \& Plass, J.L. (2002). Supporting listening comprehension and vocabulary acquisition in French with multimedia annotations. The Modern Language Journal, 86(2), 546-561.

Kanning, R.G. (1994). What multimedia can do in our classrooms. Educational Leadership, 51(7), 40-45.

Kekkonen-Moneta, S., \& Moneta, G. B., 2002. E-learning in Hong Kong: comparing learning outcomes in online multimedia and lecture versions of an introductory computing course. British Journal of Educational Technology. 33(4), 423-433.

Kutzik, J. (2005). Just-in-time technology training for emergent needs. Library Mosaics, $16(2), 8-10$.

Lau, P. (2007). Differences between audio file types 101. Canadian Musician, 29(5), 31. 
Leach, A. \& Haun, D. (2003) Deliver the lesson now: just-in-time training. Lab Management. Retrieved from http://www.mlo-online.com

Lei, S. \& Gupta, R. (2010). College distance education courses: evaluating benefits and costs from institutional, faculty and students ' ' perspectives. Distance Education, 130(4), 616-631.

Ley, T. \& Albert, D. (2003). Identifying employee competencies in dynamic work domains: Methodological considerations and a case study. Journal of Universal Computer Science, 9(12).

Liaw, S. (2008). Investigating students perceived satisfaction, behavioral intention, and effectiveness of e-learning: a case study of the blackboard system. Computers \& Education, 51, 864-873.

Mayer, R.E. (1997). Multimedia learning: Are we asking the right questions? Educational Psychologist, 32(1), 1-19.

McNeill, D., (2008). Engaging younger workers using YouTube to create rapid learning simulations. Professional Safety, 53, 56-58.

McNeill, A.L., Doolittle, P.E. \& Hicks, D. (2009). The effects of training, modality, and redundancy on the development of a historical inquiry strategy in a multimedia learning environment. Journal of Interactive Online Learning, 8(3), 225-269.

Meister, J. (2009). The power of iTunes U. Retrieved from http://newlearningplaybook.com/blog/2009/02/27/the-power-of-itunes-u/

Moller, L., Foshay, W.R. \& Huett, J. (2008). The evolution of distance education: Implications for instructional design on the potential of the web. Tech Trends, 52(3), 70-75.

Moreno, R. \& Mayer R.E. (2000). A learner-centered approach to multimedia explanations: deriving instructional design principles from cognitive theory. Interactive Multimedia Electronic Journal of Computer-Enhanced Learning. Retrieved from: http://imej.wfu.edu/articles/2000/2/05/printver.asp

Morgan, P. (2007). Adult learner satisfaction with web-based non-credit workforce training. ( Doctoral Dissertation ). Retrieved from. ProQuest Dissertation \& Theses. Proquest. 3288275.

Mulligan, D.K. (2003). Digital rights management and fair use by design. Communications of the ACM, 46(4), 31-33.

Paivio, A. (1986). Mental representations: A dual coding approach. Oxford, England; Oxford University Press. 
Plass, J.L., Chun, D.M., Mayer, R.E. \& Leutner, D. (2003). Cognitive load in reading a foreign language of verbal and spatial abilities. Computers in Human Behavior, $19,221-243$.

Pullen, J.M. (2001). Applicability of internet video in distance education for engineering.IEEE, 14-19.

Rexford, J., Sen, S., Dey, J., Feng, W., Kurose, J., Stankovig, J., \& Towsley, D. (1997). Online smoothing of live, variable-bit rate video. IEEE/ACM Trans. Networking, (2), 235-243.

Rodriguez, M., Ooms, A., \& Montañez, M. (2008). Students' perceptions of onlinelearning quality given comfort, motivation, satisfaction and experience. Journal of Interactive Online Learning, 7(2), 105-125.

Romanov, K. \& Nevgi, A. (2007). Do medical students watch video clips in elearning and do these facilitate learning?. Medical Teacher, 29, 490-494.

Schilling, K. (2009). The impact of multimedia course enhancements on student learning outcomes. Journal of Education for Library and Information Science, 50(4), 214225 .

Schwamborn, A., Thillmann, H., Opfermann, M. \& Leutner, D. (2011). Cognitive load and instructionally supported learning with provided and learner-generated visualizations. Computers in Human Behavior, 27, 89-83.

Shuck, M.B. \& Wollard, K. K. (2008). Employee engagement: Motivating and retaining tomorrow's workforce. New Horizons in Adult Education and Human Resource Development, 22(1), 48-53.

Stucken, A. (2010). What is an mp3? Retrieved from http://www.bbc.co.uk/webwise/guides/about-mp3s

Tobias, S. (2010). Generative learning theory, paradigm shifts, and constructivism in educational psychology: A tribute to Merl Wittrock. Educational Psychologist, $45(1), 51-54$.

Yvas, R., Albright, S., Walker, D., Zachariah, A. \& Lee, M.Y. (2010). Clinical training at remote sites using mobile technology: an India-USA partnership. Distance Education, 31(2), 211-226.

Wang, M., Ran, W., Liao, J., Yang,S.J.H., (2010). A performance-oriented approach to elearning in the workplace. Educational Technology \& Society, 13(4), 167-179. 
Welcome, S., Paivio, A., McRae, K. \& Joanisse, M. (2011). An electrophysiological study of task demands on concreteness effects: evidence for dual coding theory. DOI 10.1007/s00221-011-2734-8

Wingaarden, A. J., Erman, B., Matthews, E.P., Sharp, R., and Sutter, E. (2010) Multistream video conferencing over a peer-to-peer network. Bell Labs Technical Journal 15(2), 229-244. Doi:10.1002/bltj.20451

Wittrock, M. (1990). Generative Processes of Comprehension. Educational Psychologist, 24(4), 345-376.

Zhang, D. (2005). Interactive multimedia-based e-learning: a study of effectiveness. The American Journal of Distance Education, 19(3), 149-162.

Zheng, R. Z., Yang, W., Garcia, D., \& Cardenas, E.P. (2008). Effects of multimedia and schema induced analogical reasoning on science learning. Journal of Computer Assisted Learning, 24, 474-482. 


\section{APPENDIX A: SPLD Survey CBT level 1}

SPLD-Survey-CBT-Medicare 101

The LMS displays this survey with radio buttons for each anchor point. All 25 questions are displayed in one page. Learners respond to all question items and subsequently click a button labeled "Submit answers for scoring" for their answers to be recorded. Next, learners can click "return" which takes them back to the course outline to mark the course complete.

KMx - Your Prescription for Performance Page 1 of 7

1. The way the Computer Based Training (CBT) was presented helped me learn.

- Strongly Disagree

- Disagree

- Neutral

- Agree

- Strongly Agree

2. The length of the CBT was appropriate.

- Strongly Disagree

- Disagree

- Neutral

- Agree

- Strongly Agree

3. The CBT was an effective use of my time.

- Strongly Disagree

- Disagree

- Neutral

- Agree

- Strongly Agree 
4. The materials presented in the CBT were presented in a logical sequence.

- Strongly Disagree

- Disagree

- Neutral

- Agree

- Strongly Agree

5. I am satisfied with the complexity of materials that were presented in the CBT.

- Strongly Disagree

- Disagree

- Neutral

- Agree

- Strongly Agree

6. The knowledge/skills acquired in this CBT will aid me in my role.

- Strongly Disagree

- Disagree

- Neutral

- Agree

- Strongly Agree

7. I found that some materials in this CBT were not necessary/appropriate for my role.

- Strongly Disagree

- Disagree

- Neutral

- Agree

- Strongly Agree

8. I would recommend this course to my peers.

- Strongly Agree

- Agree

- Neutral

- Disagree

- Strongly Disagree

9. It was clear what was expected of me for this course.

- Strongly Disagree

- Disagree

- Neutral

- Agree

- Strongly Agree 
10. The format in which the materials were presented was appropriate for the delivery of this information.

- Strongly Disagree

- Disagree

- Neutral

- Agree

- Strongly Agree

11. The amount of information presented to me was appropriate.

- Strongly Disagree

- Disagree

- Neutral

- Agree

- Strongly Agree

12. I found the technology needed for this CBT to be easy to use.

- Strongly Disagree

- Disagree

- Neutral

- Agree

- Strongly Agree

13. I found it easy to navigate through this CBT.

- Strongly Disagree

- Disagree

- Neutral

- Agree

- Strongly Agree

14. There was an appropriate use of graphics throughout the CBT.

- Strongly Disagree

- Disagree

- Neutral

- Agree

- Strongly Agree

15. The video format aided in my understanding of the subject matter.

- Strongly Disagree

- Disagree

- Neutral

- Agree

- Strongly Agree 
16. The audio for the narration was clear. (If applicable)

- Strongly Disagree

- Disagree

- Neutral

- Agree

- Strongly Agree

- N/A

17. The narration was appropriately synchronized with the text/animation. (If applicable)

- Strongly Disagree

- Disagree

- Neutral

- Agree

- Strongly Agree

- N/A

18. The quiz questions matched the material presented. (If applicable)

- Strongly Disagree

- Disagree

- Neutral

- Agree

- Strongly Agree

- N/A

19. What did you like the most about the CBT?

20. What suggested improvements do you have? If you have a comment about a specific section, please note the section name if you can recall.

21. I would like more information on the following topics: [Topics will be relative to the subject of the e-learning course. Since this survey is attached to all online courses, topics will vary by subject matter.]

22. Why did you enroll for this course?

- I wanted to learn more about this topic.

- I was required to take it.

- I was signed up by my supervisor.

23. I have been in my current role for:

- 0 -6 months

- 6 months -1 year

- 1 year -3 years

- More than 3 years 
24. What is your current role?

- Physician

- Nurse

- Pharmacist

- Pharmacy Technician

- Social Worker

- Licensed Counselor

- Other

25. If you answered "Other" for the previous question, please enter your role here. 


\section{CURRICULUM VITAE}

NAME:

ADDRESS:

DOB:

EDUCATION

\& TRAINING:
Hardy Adrian MacKenzie

8717 Deer Point Ct. Louisville, KY 40242

Guatemala, Guatemala - October 28, 1971

B.S., Business Administration

University of Louisville

$1996-1998$

M.Ed., Instructional Technology

University of Louisville

$2000-2002$

Ph.D., Educational Leadership \& Organizational

Development

University of Louisville

$2003-2013$

EXPERIENCE: Learning Manager, Senior Products Segment

Humana Inc.

2011 - Present

Learning Technology Consultant, Information Technology Humana Inc. $2010-2011$

Learning Technology Consultant, Clinical Learning \& Development

Humana Inc.

$2008-20010$

Learning Consultant, Clinical Learning \& Development Humana Inc.

$2006-2008$ 
Part Time Instructor Graduate Program

University of Louisville, College of Education

$2002-2010$

Computer Science Teacher

Assumption High School

$2001-2006$

AWARDS:

Dean's List

University of Louisville

Spring 1998

Dean's List

University of Louisville

Fall 1997

NATIONAL

MEETING

PRESENTATIONS: Central States Conference of Foreign Language

Best of Kentucky

Using Producer in the Classroom

Dearborn Michigan

2004

Best of Kentucky

Using Producer in the Classroom

Kentucky Conference Teaching of Foreign Language

2002 